\title{
The EFSUMB Guidelines and Recommendations for Musculoskeletal Ultrasound - Part II: Joint Pathologies, Pediatric Applications, and Guided Procedures
}

\section{EFSUMB-Leitlinien und -Empfehlungen für den muskuloskelettalen Ultraschall - Teil Il: Gelenkpathologien, pädiatrische Anwendungen und geführte Verfahren}

Authors

Esperanza Naredo', Sebastián C. Rodriguez-Garcia², Lene Terslev³ ${ }^{2}$ Carlo Martinoli $^{4}$, , Andrea Klauser ${ }^{6}$, Wolfgang Hartung ${ }^{7}$, Hilde B. Hammer ${ }^{8}$, Vito Cantisani ${ }^{9}$, Federico Zaottini ${ }^{4,}{ }^{5}$, Violeta Vlad ${ }^{10}$, Jacqueline Uson ${ }^{11}$, Plamen Todorov ${ }^{12}$, Christian Tesch ${ }^{13}$, Iwona Sudoł-Szopińska ${ }^{14}$, Paolo Simoni ${ }^{15}$, Oana Serban ${ }^{16}$,

Luca Maria Sconfienza ${ }^{17,}{ }^{18}$, Xavier Sala-Blanch ${ }^{19}$, Athena Plagou ${ }^{20}$, Riccardo Picasso ${ }^{4,5}$, Levent Özçakar ${ }^{21}$, Aurelie Najm²2, Ingrid Möller ${ }^{23}$, Mihaela Micu ${ }^{24}$, Dolores Mendoza-Cembranos ${ }^{25}$, Peter Mandl26, Clara Malattia ${ }^{27}$, Manuela Lenghel ${ }^{28}$, Jens Kessler ${ }^{29}$, Gabriella lohom ${ }^{30}$, Javier de la Fuente ${ }^{31}$, Maria Antonietta D’Agostino ${ }^{32}$, Paz Collado ${ }^{33}$, Angel Bueno ${ }^{34}$, David Bong ${ }^{23}$, Fernando Alfageme ${ }^{35}$, Diana Bilous ${ }^{16}$, Roxana Gutiu ${ }^{16}$, Anamaria Marian ${ }^{16}$, Michael Pelea ${ }^{16}$, Daniela Fodor ${ }^{16}$

Affiliations

1 Department of Rheumatology, Bone and Joint Research Unit. Hospital Universitario Fundación Jiménez Díaz, IIS Fundación Jiménez Díaz, and Universidad Autónoma de Madrid, Madrid, Spain

2 Rheumatology Department, La Princesa University Hospital, Princesa Health Research Institute, Madrid, Spain

3 Copenhagen Center for Arthritis Research, Center for Rheumatology and Spine Diseases, Rigshospitalet, Glostrup, Denmark; Department of Clinical Medicine, University of Copenhagen, Copenhagen, Denmark

4 Department of Health Science - DISSAL, University of Genova, Italy

5 UO Radiologia, IRCCS Policlinico San Martino, Genova, Italy 6 Department of Radiology, Medical University Innsbruck, Section Head Rheumatology and Sports Imaging, Innsbruck, Austria

7 Clinic for Rheumatology and Clinical Immunology, Asklepios Clinic, Bad Abbach, Germany

8 Department of Rheumatology, Diakonhjemmet Hospital and Faculty of Medicine, University of Oslo, Oslo, Norway

9 Department of Radiological, Oncological and Anatomopathological Sciences, "Sapienza” University, Rome, Italy

10 Sf. Maria Hospital, Rheumatology Department, Bucharest, Romania

11 Department of Rheumatology Hospital Universitario Móstoles, Universidad Rey Juan Carlos, Madrid, Spain

12 Department of Internal Disease Propaedeutic and Clinical Rheumatology, Medical University of Plovdiv, Plovdiv, Bulgaria

13 Orthopedics and Trauma Surgery, Praxis, Hamburg, Germany

14 Department of Radiology, National Institute of Geriatrics, Rheumatology and Rehabilitation, Warsaw, Poland
15 Paediatric Imaging Department, “Reine Fabiola” Children's University Hospital, Université Libre de Bruxelles, Brussels, Belgium

$162^{\text {nd }}$ Internal Medicine Department, "Iuliu Hatieganu" University of Medicine and Pharmacy, Cluj-Napoca, Romania

17 IRCCS Istituto Ortopedico Galeazzi, Milano Italy

18 Department of Biomedical Sciences for Health, University of Milano, Milano, Italy

19 Department of Anaesthesiology, Hospital Clinic, Department of Human Anatomy, Faculty of Medicine, University of Barcelona, Spain

20 Ultrasound Unit, Private Radiological Institution, Athens, Greece

21 Department of Physical and Rehabilitation Medicine, Hacettepe University Medical School, Ankara, Turkey

22 Institute of Infection, Immunity and Inflammation, College of Medical Veterinary and Life Sciences, University of Glasgow, Glasgow, United Kingdom

23 Instituto Poal de Reumatologia Barcelona, EULAR Working Group Anatomy for the Image, University of Barcelona, International University of Catalunya, Spain

24 Rheumatology Division, 2nd Rehabilitation Department, Rehabilitation Clinical Hospital Cluj-Napoca, Romania

25 Department of Dermatology. Hospital Universitario Fundación Jiménez Díaz.Madrid, Spain

26 Division of Rheumatology, Medical University of Vienna, Vienna, Austria

27 UOC Clinica Pediatrica e Reumatologia, IRCCS Istituto Giannina Gaslini, Department of Neurosciences, Rehabilitation, Ophthalmology, Genetic and Maternal Infantile Sciences (DINOGMI) University of Genoa, Genoa, Italy

28 Radiology Department, "Iuliu Hatieganu” University of Medicine and Pharmacy, Cluj-Napoca, Romania 
29 Department of Anaesthesiology, Division of Pain Medicine, University Hospital Heidelberg, Heidelberg, Germany

30 Department of Anaesthesiology and Intensive Care Medicine, Cork University Hospital and University College Cork, Cork, Ireland

31 Orthopedic Department, Clinica Pakea de Mutualia, San Sebastián, Spain.

32 Istituto di Reumatologia Università Cattolica del Sacro Cuore, UOC Reumatologia, Fondazione Policlinico Universitario Agostino Gemelli, IRCCS, Rome, Italy 33 Rheumatology Department, Transitional Care Clinic, Hospital Universitario Severo Ochoa, Madrid, Spain

34 Department of Musculoskeletal Radiology, Hospital Universitario Fundación Alcorcón, Madrid, Spain

35 Dermatology Department, Hospital Universitario Puerta de Hierro Majadahonda, Madrid, Spain

Key words ultrasound, musculoskeletal, EFSUMB, guidelines, recommendations

received 24.03.2021

accepted 07.08.2021

published online 03.11.2021

Bibliography

Ultraschall in Med 2022; 43: 252-273

DOI 10.1055/a-1640-9183

ISSN $0172-4614$

(C) 2021. Thieme. All rights reserved.

Georg Thieme Verlag KG, Rüdigerstraße 14,

70469 Stuttgart, Germany

Correspondence

Dr. Esperanza Naredo

Rheumatology, Hospital Universitario Fundación Jiménez

Díaz, Avda Reyes Católicos 2, 28040 Madrid, Spain

Tel.: +34/91/5504800

enaredo@ser.es
Supplementary material is available under
https://doi.org/10.1055/a-1640-9183

\section{ABSTRACT}

The second part of the Guidelines and Recommendations for Musculoskeletal Ultrasound (MSUS), produced under the auspices of EFSUMB, following the same methodology as for Part 1, provides information and recommendations on the use of this imaging modality for joint pathology, pediatric applications, and musculoskeletal ultrasound-guided procedures. Clinical application, practical points, limitations, and artifacts are described and discussed for every joint or procedure. The document is intended to guide clinical users in their daily practice.

\section{ZUSAMMENFASSUNG}

Der zweite Teil der Leitlinien und Empfehlungen für den muskuloskelettalen Ultraschall (MSUS), der unter der Schirmherrschaft der EFSUMB erstellt wurde, folgt der gleichen Methodik wie Teil 1 und enthält Informationen und Empfehlungen zum Einsatz dieses bildgebenden Verfahrens in der Gelenkpathologie, bei pädiatrischen Anwendungen und bei muskuloskelettalen ultraschallgeführten Verfahren. Klinische Anwendung, praktische Aspekte, Limitationen und Artefakte werden für jedes Gelenk oder Verfahren beschrieben und diskutiert. Dieses Dokument soll den klinischen Anwendern in ihrer täglichen Praxis als Leitfaden dienen.

\section{Joint pathology}

\subsection{Shoulder}

\section{Background}

US has been used extensively in the diagnosis of various intra- and periarticular pathological conditions of the shoulder.

\section{Clinical applications}

US is an essential imaging method of glenohumeral joint (GHJ) evaluation, as shoulder swelling is unusual and effusion is not detected by X-ray [1, 2]. US detects intra-articular effusion/synovitis - frequently in RA and polymyalgia rheumatica (PMR) [3, 4], but rarely in osteoarthritis (OA) and spondyloarthritis (SpA) [5]. Effusions are not found in asymptomatic patients and are rarely observed in random painful shoulders [6, 7]. Although magnetic resonance imaging (MRI) detects effusions more often than US, it is not compatible with dynamic shoulder examination $[2,8]$.

Proliferative synovitis of $\mathrm{GHJ}$ can be detected in the posterior recess, axillary recess, or biceps tendon (BT) sheath in inflammatory arthritis, although synovitis in the BT sheath has low specificity for RA [3]. The power Doppler signal can be detected inside the posterior recess or around the BT but not in the axillary recess [3]. The power Doppler signal around the BT can distinguish RA from OA [9]. In particular, power Doppler detection of the synovial signal in the posterior $\mathrm{GH}$ ] recess has shown excellent reliability [10].

Rotator cuff disease (tears, tendinopathy, impingement) is the most common cause of shoulder pain, accounting for $65 \%$ to $70 \%$ of cases [11]. There is consistent data on similar diagnostic accuracy of US and MRI in rotator cuff tears [12]. A meta-analysis comparing US to MRI and MR arthrography (MRA) showed that US 
diagnostic performance is equal to that of MRI but inferior to MRA. The pooled sensitivity and specificity of US for detecting full- and partial-thickness rotator cuff tears was reported to be $92.3 \%$ and $94.4 \%$, and $66.7 \%$ and $93.5 \%$, respectively [13]. In addition, US was found to be highly specific for the detection of recurrent rotator cuff tears and more specific than MRI for the detection of partial-thickness tears [14, 15]. US was shown to have a low level of interobserver variability for the detection, classification, and localization of rotator cuff tears [16] as well as for assessing fibrillar disruption, neovascularity, and the number and length of calcifications in rotator cuff tendinopathies [17]. A supraspinatus tendon thickness of $>6 \mathrm{~mm}$ or abnormal tendon echo-structure can be used with equal accuracy to MRI to diagnose supraspinatus tendinopathy [18].

The diagnosis of adhesive capsulitis (AC) of the shoulder is based on clinical findings but imaging modalities can be used to confirm the diagnosis [19]. US may help identify several morphological and functional alterations at the level of the $\mathrm{GH}$ J capsule, rotator interval [19-22], and supraspinatus and subscapularis tendon gliding [23]. The coraco-humeral ligament (CHL) and inferior $\mathrm{GH}$ j capsule were reported to be significantly thickened in $A C$ when compared to other shoulder pathologies and asymptomatic shoulders [20, 23, 24] and correlated with MRI measurements [19]. Capsular enhancement was detected using contrast-enhanced US and this parameter was comparable to MRI findings [21]. Limitation of the rotator cuff tendon gliding and the presence of hypoechoic vascular soft tissue at the rotator interval level is found in AC [25].

Shoulder instability primarily affects young active people as a result of an acute injury or overuse [26]. MRI is more accurate in comparison to other imaging techniques [27], but US can add important information during pre- and postoperative shoulder assessment [28-30].

US is a sensitive and specific imaging tool for identifying shoulder dislocation and reductions [28, 31] and may deliver real-time pre- and postoperative information about the structural alterations of the labrum, glenoid rim, humeral head, and capsule as well as about shoulder dynamics [29, 30].

Dynamic US maneuvers are valid and reproducible for the assessment and quantification of inferior $\mathrm{GHJ}$ laxity when compared to stress radiography [32] enabling the identification of athletes at risk of shoulder instability [33].

Practical points, limitations, and artifacts in shoulder pathology are detailed in Supplementary Tables 1 and 2.

\section{Recommendations}

1. US should be used to elucidate the origin of both inflammatory and noninflammatory shoulder pathologies (LoE 1, SoR strong). Broad consensus (26/5/5, 84\%)

2. Color/power Doppler should be used to quantify the degree of inflammation in the rheumatoid shoulder (LoE 1, SoR strong). Broad consensus (26/8/2, 77\%)

3. US should be considered the first-line imaging modality in rotator cuff pathology evaluation (LoE 1, SoR strong). Strong consensus (33/1/2, $97 \%)$
4. US should be considered for identifying shoulder dislocation and reduction (LoE 1, SoR strong). Broad consensus (25/8/3, $76 \%$ )

\subsection{Elbow}

\section{Background}

US findings supporting the diagnosis of elbow pathology complement those of clinical examination and other imaging methods. Dynamic maneuvers during examination, facilitated by patient positioning, are feasible and offer an advantage over MRI examination. High-frequency US is sensitive for detecting intra-articular alterations in the elbow joint (effusions, synovitis, loose bodies, cartilage degeneration) and for assessing medial joint stability [34].

\section{Clinical application}

Effusions accumulate in the coronoid and radial fossa, examined via the anterior approach with the elbow extended. For the olecranon fossa assessment, examination with the elbow in flexion allows identification of 1 to $3 \mathrm{ml}$ of fluid, thus rendering US more sensitive than radiography for diagnosing effusions. MRI, however, remains the most sensitive for identifying effusions, regardless of joint position or location [35, 36].

In inflammatory rheumatic diseases (e. g., RA), comparison of clinical examination and US evaluation showed only fair agreement, with US improving the accuracy of diagnosing synovitis compared to clinical examination [37, 38]. Furthermore, when comparing US to radiography, sonographically visible changes were detected in $24 \%$ of patients graded Larsen 0 [39]. Therefore, US is particularly valuable for detecting early stages of synovitis and minor erosions, showing intra- and interobserver reliability of $90.8 \%$ and $88.8 \%$, respectively [40].

OA affects mainly the radiohumeral joint, where US allows for the humeral and radial cartilage thickness measurement with a mean of $1.2 \mathrm{~mm}$, showing significantly reduced values in $\mathrm{OA}$ [41]. Also, the posterolateral radiohumeral plica may be evaluated, showing that OA may result in plica reduction associated with morphological changes [41]. In addition, lateral synovial fringe impingement at the radiohumeral joint may be assessed $[42,43]$. US can detect loose bodies located between the cartilage and anterior or posterior fat pad, rarely in the small radial recess [44].

Assessment of medial elbow stability [45], indicative of the risk of ulnar collateral ligament (UCL) injury among professional sport players [46], requires US dynamic maneuvers. The thickness of the anterior bundle of the UCL and the width of the ulno-humeral joint can be measured in flexion, both at rest and with an applied valgus load. The anterior bundle of the UCL was found to be significantly thicker and the ulno-humeral joint space was significantly wider in the dominant arm both at rest and with applied valgus load, in asymptomatic and symptomatic baseball players alike [47, 48]. Hypoechoic foci and calcifications were found to be significantly more common in the dominant arm $[45,49,50]$.

Practical points, limitations, and artifacts in elbow pathology are detailed in Supplementary Tables 1 and 2. 


\section{Statement}

1. The sensitivity of elbow joint US examination to detect effusion and synovitis can be increased by dynamic evaluation, using the volar approach in extension for anterior recesses and the dorsal approach in flexion for the olecranon recess ( $L O E 2)$. Strong consensus $(29 / 1 / 6,97 \%)$

\section{Recommendations}

1. US is recommended to assess synovitis and erosions in inflammatory disease of the elbow (LoE 2, SoR strong). Broad consensus (32/2/2. 94\%)

2. US imaging should be used to assess medial elbow instability as a result of ulnar collateral ligament injury (LoE 2, SoR strong). Broad consensus (26/3/7, $90 \%)$

\subsection{Wrist and hand}

\section{Background}

Introduction of high-frequency probes led to obtaining high-resolution images of small hand and wrist structures, allowing US to rival MRI for many indications. US can be used as the primary imaging modality for many conditions in the hand and wrist with the advantage of dynamic imaging abilities providing insights into pathologies inaccessible with static imaging modalities such as MRI and computed tomography (CT). High-frequency US is sensitive for detecting intra-articular alterations in hand and wrist joints such as effusions and synovial hypertrophy. Normal joint recess thickness has been described as $\leq 2.9 \mathrm{~mm}$ for the dorsal wrist, $3.4 \mathrm{~mm}$ for the volar wrist, $\leq 1.9 \mathrm{~mm}$ for the volar metacarpophalangeal (MCP) joint, and $\leq 1.6 \mathrm{~mm}$ for the proximal interphalangeal (PIP) joint [51]. The sensitivity of the US examination can be increased by using both the palmar and dorsal approach [52]. Knowledge of pitfalls is essential [53].

B-mode and Doppler US have shown validity and reproducibility for detecting and quantifying synovial inflammation in wrist/ finger joints when compared with histological findings in RA [5458]. US contrast media allows finger joint vascularity assessment and quantification at the microvascular level [59-62].

Cartilage assessment was shown to be feasible in both degenerative and crystal deposition disease [63, 64]. US assessment of articular cartilages and detection of RA erosions in accessible aspects of finger joints has been successfully validated using cadaver specimens [63] and CT/micro-CT [65, 66], respectively.

\section{Clinical applications}

US is able to detect subclinical synovitis, even in RA patients in synthetic or biological therapy-induced clinical remission [67]. This can predict joint structural damage appearance and progression [68] as well as disease flare [69]. In addition, US is substantially more sensitive than conventional radiography for detecting early bone erosions [70] and cartilage damage [71] in RA target joints of the hand.

The predictive value of US in relation to the development of Doppler-positive synovitis in the target areas, such as the wrist and MCP joints, or early erosions in specific sites of MCP joints in patients with inflammatory arthralgia or in those with early undifferentiated arthritis has been proven [72, 73].
US assessment of synovitis in the wrist and fingers has shown the best accuracy-feasibility balance in reduced joint count scores at the patient level for US monitoring [74] and subclinical inflammation detection [75] in RA patients.

In addition to synovitis, psoriatic arthritis (PsA) is characterized by enthesitis, tenosynovitis, and dactylitis, all of which are readily detectable on US. US detects both articular and peri-articular inflammation in early [76] as well as established [77] disease, which correlates with clinical disease activity [78] and was shown to be sensitive to change [77]. Similar to RA, US-detected subclinical synovitis is very common in early PsA and led to the majority of oligoarthritis patients being reclassified as having polyarthritis [76].

In connective tissue diseases such as systemic lupus erythematosus (SLE) [79, 80], primary Sjögren's syndrome (pSS) [81], and mixed connective tissue disease (MCTD) [82], US reveals subclinical synovitis located especially on the MCPs and wrist in patients without joint symptoms and correlates with clinical disease activity indices $[83,84]$. Tenosynovitis is the most common finding in systemic sclerosis [85] and, similarly to SLE, mostly affects the wrist and MCP joints [86].

In hand OA, US-detected features of inflammation, in particular power Doppler signals, are associated with the development of erosions, more severe radiographical damage, and reduced cartilage thickness [87-89]. Both Doppler flow and grayscale signs of synovitis are associated with pain $[90,91]$. US is a reliable and more sensitive imaging modality than conventional radiography for detecting erosions and osteophytes [92, 93].

US is helpful in the diagnostic workup of finger joint trauma by detecting collateral ligament tears, palmar plate injuries, thumb sesamoid fractures, clinically unsuspected synovial cysts, thickened joint capsules, fibrous tissue, and fluid collections, especially during dynamic examination and thus may help improve outcomes [94-96].

Practical points, limitations, and artifacts in wrist and hand pathology are detailed in Supplementary Tables $\mathbf{1}$ and $\mathbf{2}$.

\section{Recommendations}

1. US should be considered to detect joint inflammation in rheumatoid arthritis in order to optimize management, particularly in clinical scenarios such as early diagnosis or evaluation of residual inflammation in clinical remission (LoE 2, SoR strong). Strong consensus (34/0/2, $100 \%)$

2. US should be considered to detect the articular and peri-articular involvement of the wrist and hand in early and established psoriatic arthritis and to provide information on disease activity (LoE 2, SoR strong). Broad consensus (31/2/3, 94\%)

3. US may be used to detect both synovitis and tenosynovitis in connective tissue diseases. (LoE 2, SoR weak). Broad consensus $(31 / 2 / 3,94 \%)$

4. US should be considered to detect inflammation in hand osteoarthritis (LoE 2, SoR strong). Strong consensus (33/1/2, 97 \%) 


\subsection{Hip}

\section{Background}

The hip joint can be affected by inflammatory and degenerative conditions leading to effusion and synovitis. Furthermore, proliferative morphologic bone alterations whether developmental, traumatic, related to childhood orthopedic conditions, iatrogenic, or idiopathic (e.g., OA) may, along with labral changes, cause impingement or decreased range of motion often requiring surgical intervention. In the postoperative period, hip symptoms are not infrequent, and US may be useful in assessing the cause of the symptoms. Hip pathology may also be seen in trauma leading to hematoma and/or anterior labral tear.

\section{Clinical application}

\section{Arthritic conditions}

US is more sensitive than clinical examination for the assessment of synovitis and effusion in the hip [97, 98] but less sensitive compared to MRI $[99,100]$. US is a reproducible method for the assessment of changes in the osseous surface, synovitis, and effusions [101, 102]. The anterior column-capsule distance has been reported to be $\geq 7 \mathrm{~mm}$, showing good sensitivity for effusion/ synovitis, whereas a cut-off $\geq 9 \mathrm{~mm}$ improves the specificity [ 99 , 103]. In suspected crystal arthritis, US should be regarded as the first-line imaging technique for hip assessment because of its reliability in detecting crystal deposits and its safety compared to conventional radiography $[104,105]$. US may be used to monitor treatment in inflammatory arthritis [102, 106-108].

\section{Femoroacetabular impingement (FAI)}

FAl is an important cause of hip pain in younger patients. In juvenile males a strong association has been noted between high intensity weightbearing sports and cam morphology, which is a strong risk factor OA and hip replacement [109-111]. The diagnosis of FAl is based on clinical symptoms, physical examination, and initial conventional radiography. US has been evaluated for the diagnosis of cam deformity and in follow-up after surgical resection and has compared favorably to X-ray, MRI, and the gold standard MRA [112-115]. US evaluation of the morphologic appearance of the head-neck junction and measurement of the " $\alpha$-angle" (along with other measurements) have been assessed and found to be comparable with other imaging techniques [114-116].

\section{Anterior labrum tear (ALT)}

Using US, labral tears may appear as labral enlargement with intra-substance hetero-echogenicity, labral displacement or the absence thereof, hypoechoic clefts or labral intrasubstance or para-labral cysts [117]. US is comparable to MRI for labral tears but inferior to MRA or CT arthrography (used when MRA is contraindicated) [118-120].

\section{Total hip arthroplasty (THA)}

US of the postoperative hip joint allows assessment of the periprosthetic area of the hip and surrounding tissues. In the early postoperative phase, US can detect fluid collection and hematoma, thereby helping to determine further treatment [121-123]. In the later postoperative phase, US can help in the diagnosis of pathology such as iliopsoas bursitis, muscle atrophy, fluid collections as well as in the detection and routine monitoring of pseudotumors after a metal-on-metal (MoM) hip arthroplasty [124126]. Metal artifact reduction sequence MRI (MARS MRI) is the gold standard for the assessment of postoperative hips. US, with its reported high sensitivity for detection, can play a critical role in the diagnosis and routine monitoring of pseudotumors in asymptomatic patients [126-128].

Practical points, limitations, and artifacts in hip pathology are detailed in Supplementary Tables 1 and 2.

\section{Statement}

1. Ultrasound of the hip is more sensitive than clinical examination but not as sensitive as MRI for detecting synovitis and effusion (LoE 4). Broad consensus (30/4/2, $88 \%$ ).

\section{Recommendations}

1. US might be used to monitor the treatment of hip inflammation. Timing of repeat US is dependent on the clinical circumstances (LoE 2, SoR weak). Broad consensus (26/6/4, $81 \%$ )

2. Following metal-on-metal total hip arthroplasty, US is recommended as the initial screening tool and for regular surveillance in pseudotumor diagnosis in asymptomatic patients, as US has the same diagnostic accuracy as metal artifact reduction sequence MRI (LoE 2 SoR strong). Broad consensus (29/2/ $5,94 \%)$

3. US may be used to evaluate patients clinically suspected for femoroacetabular impingement (LoE 4, SoR weak). Broad consensus (27/7/2, 79\%)

4. US may be used for detecting hip anterior superior labrum tears (LoE 4, SoR weak). Broad consensus (28/7/1, $80 \%$ )

\subsection{Knee}

\section{Background}

US detection and quantification of inflammatory findings in the knee have been validated using MRI [129] and histology [130]. US has also shown great value in the detection of crystal deposition in several structures of the knee such as the articular cartilage, menisci, and tendons [131-133]. In OA, the assessment of meniscal protrusion, articular cartilage degeneration, synovitis, osteophytes, and Baker's cysts (popliteal cyst) are the main uses of US. After history and clinical examination, US is the first choice for imaging of knee injuries, e. g., sprains and direct impact.

\section{Clinical application}

\section{Inflammatory arthritis}

US has shown a greater sensitivity than clinical evaluation for the detection of knee inflammation, i. e., intra-articular effusion, synovial proliferation, and synovial inflammatory activity, i.e., synovial blood flow in immune-mediated arthritis such as RA [134] or SLE [135] as well as in crystal arthritis such as gout and 
calcium pyrophosphate deposition disease (CPPD) [136]. US is also more sensitive than clinical examination for detecting Baker's cysts [134].

\section{Crystal arthritis}

US allows differentiation between CPPD and urate crystal deposits based on the distribution of the pathological findings. These are hyperechoic foci within the articular cartilage substance in CPPD $[133,136,137]$ and a thick hyperechoic enhancement of the synovial surface of the cartilage irrespective of the insonation angle of the US beam (the double contour sign) $[138,139]$ in gout. It has been widely demonstrated that the capacity of US to detect intra-articular CPPD crystals in the knee is superior to that of conventional radiography $[131,132,140,141]$.

\section{Osteoarthritis}

US and clinical findings (e. g., pain, function) correlate in knee OA $[142,143]$. US has demonstrated good reproducibility in the assessment of the osteoarthritic knee [144]. While prompt detection of fluid is contributory to subsequent intervention [145], the presence of US-detected effusion greater than $4 \mathrm{~mm}$ has also been reported to predict subsequent joint replacement [146].

Similarly, an initial US finding of meniscal protrusion was found to be predictive of radiographic OA [147]. Of note, both quantitative and semiquantitative assessments of meniscal protrusion seem reliable when compared with MRI [148]. Undoubtedly, dynamic scanning is better for functional assessment of meniscal protrusion [149].

For the detection of osteophytes, US provides superior sensitivity compared to conventional radiographs for the detection of osteophytes [150]. Grading scales for medial femoral osteophytes have also been developed, with good agreement with the Kellgren-Lawrence grading [151].

US and MRI were found to be comparable with respect to assessing cartilage defects [152]. Semi-quantitative grading and thickness measurements of the articular cartilage were sufficiently correlated with MRI [153] and histological findings [154]. Normative reference values for any of the aforementioned data can be readily established among populations [155].

\section{Knee injuries}

If a fracture in the area of the patella and the tibial head is suspected, US scanning of the most painful region in two planes has shown a high sensitivity and specificity for detecting a cortical break [156]. Nevertheless, X-rays are mandatory in these cases. Muscle contusions, joint effusions and popliteal cysts are reliably detected by US [157]. A distortion injury can lead to rupture of the capsule, the medial patellofemoral ligament, the medial and lateral collateral ligament, the tendons of the semimembranosus, semitendinosus and gastrocnemius on the inside and the popliteus on the outside of the knee. The ability of US to detect these lesions is comparable with that of MRI.

US of the meniscus, especially medially, has a high negative predictive value of $93 \%$ and an acceptable specificity for meniscal lesions [158]. However, if damage to the meniscus with a possible requirement of an operative procedure is suspected, MRI is neces- sary [159]. Although in the area of the medial meniscus, the anterior horn, the pars intermedia, and the posterior horn can be assessed sonographically with regard to the outer contour, the internal structure is not sufficiently reliable to differentiate a radial and a horizontal tear [160]. If the meniscus is subluxed or even dislocated, this can be reliably detected with US, but the cause cannot always be specified. Dynamic examination of the posterior corner of the capsule and the posterior horn of the meniscus is particularly helpful. A bucket-handle tear of the medial meniscus is clearly recognizable [161]. A discoid meniscus, which typically affects the outer meniscus, can be easily visualized.

All ligaments of the knee joint except the two cruciate ligaments are superficially opposed and thus amenable to US assessment. Ruptures and distortions with intra-ligamentary fluid accumulation may be differentiated through morphological structural changes and abnormalities on power Doppler [162]. The medial collateral ligament and the medial patellofemoral ligament are particularly accessible [163]. The anterolateral ligament, visible on US, has been extensively examined due to its importance for the anterolateral rotational instability in ruptures of the anterior cruciate ligament [164]. After a patella dislocation, the visualization of the ruptured medial patellofemoral ligament is of great importance and can be performed sonographically [165]. The posterior cruciate ligament can be easily assessed by direct visualization of the distal two-thirds aspect [166]. This is not reliable in the clinically more important proximal third or the proximal two-thirds of the anterior cruciate ligament [167]. In the dynamic assessment of the two cruciate ligaments, a number of studies have left no doubt as to the value of the US Lachman test [168170].

Practical points, limitations, and artifacts in knee pathology are detailed in Supplementary Tables $\mathbf{1}$ and 2.

\section{Recommendations}

1. US could be used to detect and characterize knee inflammatory abnormalities when clinical assessment is insufficient or inconclusive (LoE 3, SoR weak). Broad consensus (26/3/7, $90 \%$ )

2. In crystal-related arthritis of the knee (with or without symptoms), US is recommended to increase diagnostic accuracy (LoE 2, SoR strong). Strong consensus (31/0/5, $100 \%$ )

3. US should be used to detect effusion/synovitis, cartilage damage, early bone proliferation and meniscal protrusion in the diagnosis and management of knee osteoarthritis (LoE 2b, SoR strong). Strong consensus (33/1/2, $97 \%)$

\section{Ankle and foot}

\section{Background}

Due to the high number of joints found in the ankle and foot and the complexity of local anatomy, US examination needs to follow standardized protocols $[171,172]$. In healthy subjects, synovial fluid and synovial hypertrophy in the ankle and especially in the foot joints have higher prevalence compared with other joints, in correlation with biomechanical factors, age, and pregnancy [173, 174] 


\section{Clinical application}

In contrast to the high interest in US of the hand and wrist in RA patients, fewer studies on ankle and foot involvement have been published [175]. Clinical detection of synovitis is more difficult than in the wrist and hand [176]. However, US is more sensitive for detecting ankle and foot synovitis compared to clinical examination [177, 178]. The added value of US in detecting inflammatory lesions $[176,179,180]$ is proven, showing the importance of the method in characterizing disease activity. In the ankle and midfoot, the tibiotarsal (TT) and talonavicular joints are the most frequently affected joints [181-184] while in the forefoot the metatarsophalangeal (MTP) joints, especially MTP II-V, are most affected $[183,185]$. Using US, subclinical synovitis was found in $25 \%$ of RA patients in clinical remission [186] and the presence of the power Doppler signal in MTP joints showed predictive value for unstable remission [186] and radiographic progression [187]. Compared to X-ray, US performs better in the evaluation of MTP joint articular cartilages [188] and erosions [189]. US and MRI had comparable sensitivity for the detection of synovitis in MTP or tarsal joints [190-192] and very good agreement (96\%) for MTP erosions [190]. Interobserver agreement was very good or good for the US detection of ankle and foot synovitis [193].

In PsA, US more frequently detected features of active disease at the MTP level compared to clinical examination [194]. The presence of MTP synovitis, erosion, and subluxation was predominately responsible for painful MTP [195]. US and MRI had high concordance ( $85 \%$ to $100 \%$ ) for destructive changes and moderate concordance for inflammatory findings (73\% to $100 \%$ ), with both techniques being more sensitive compared to X-ray and clinical examination [196]. Compared with MRI, X-ray, and scintigraphy, the specificity of US was between $84 \%$ and $94 \%$, depending on the pathological joint [197]. Agreement between US and MRI was higher regarding effusion and synovitis in MTP I, II and V, compared with MTP III and IV [197]. MTP joints were included in US composite scoring systems which have shown utility in monitoring response to therapy $[198,199]$. US-detected persistent synovitis or enthesitis after 6 months of treatment proved to be an independent predictor of future structural progression [200]. Also, detection of at least one joint with active power Doppler synovitis (including TT and MTP) in PsA patients in remission, led to flare during follow-up in $65 \%$ of cases (relative risk $=11,95 \% \mathrm{Cl}$ 2.8-44, p<0.001) [201].

In gout, MTP I and TT are the most frequently affected joints. US is a sensitive imaging technique for the evaluation of joint pathology in acute gout attacks, the early detection of erosive joint damage, the assessment of monosodium urate deposits, and the guiding of intra-articular injections, with high sensitivity and specificity [202-206]. High intra-observer agreement was found for elementary lesions in gout [207], and the presence of the double contour sign in the first metatarsal, talar, second MCP, or femoral articular cartilage has good sensitivity and specificity for the diagnosis of gout [208].

An early study, focused on joint involvement in SLE [209], reported that MTP joints (especially MTP II) were the most affected site $(72.6 \%)$ with significant differences compared with the wrist, MCP, and PIP (joint effusion, synovial hypertrophy, or synovitis).
US inflammatory scores, as indicators of severity of local joint involvement, have the highest value for the MTP joints. Synovitis and synovial power Doppler vascularity were more commonly detected in MTP II and IV [210]. The presence of MTP synovial hypertrophy in $80 \%$ of the SLE cases with power Doppler signal in only $10 \%$ of cases, was related to mechanical tissue irritation [211].

In Löfgren syndrome with ankle involvement, articular synovitis is rare, mild, and without significant power Doppler activity [212, 213]. Talocrural, subtalar, and Lisfranc joints can be affected ( $25 \%$ effusion, $17.5 \%$ synovitis, and $7.5 \%$ power Doppler signal), with bilateral arthritis rarely being present [139].

Elementary lesions of foot $\mathrm{OA}$, including inflammatory lesions (synovial hypertrophy, joint effusion, power Doppler signal) and structural abnormalities (cartilage damage and osteophytes) have been evaluated leading to the conclusion that US is a reliable tool for assessing inflammatory lesions in foot OA [214]. The prevalence of US pathological findings in patients with foot OA is high, both in the forefoot and midfoot [215]. Osteophytes are associated with the presence of MTP I pain and together with power Doppler synovitis, with worse patient-reported function [216].

In marathon runners, the acute physical stress does not produce significant changes or effusion in the talocrural joints [217]. In contrast, in patients with ankle sprains, the presence of talocrural effusion on US indicates severe ankle sprain [218].

Practical points, limitations, and artifacts in ankle and foot pathology are detailed in Supplementary Tables 1 and 2.

\section{Recommendations}

1. In patients diagnosed with RA, PsA, LES, and gout presenting with ankle or foot joints symptoms, US should be used for the differential diagnosis and management of the arthritis (LoE 2b, SoR strong). Strong consensus (33/1/3, $97 \%$ )

2. US might be used as a complementary imaging technique for the evaluation of the traumatic ankle and foot joint lesions (LoE 5, SoR weak). Broad consensus (31/2/3, $94 \%$ )

\section{Pediatric applications}

\section{Background}

MSUS is a particularly attractive imaging technique in the pediatric population. Besides benefits for children (no ionizing radiation or sedation required), the use of US in evaluating disease has been steadily increasing throughout the world because of its accessibility for clinicians, portability, real-time imaging capabilities and low economic cost.

In addition to a detailed anatomy description of joints and soft tissues on B-mode, Doppler US provides real-time assessment of the blood flow and its anomalies [219-221]. Establishing US normality in children is key to both US standardization and accurate diagnosis.

For many years, US has been used for the diagnosis of developmental dysplasia of the hip (DDH) [222]. US is well suited for imaging all peripheral joints. It enables the identification and differentiation of intra- and peri-articular structures and, consequently, 
enhanced disease assessment. Therefore, it is particularly useful in patients with Juvenile Idiopathic Arthritis (JIA) [223]. Moreover, US can be used for guiding biopsies of tumors and cystic lesions and for supporting therapeutic strategies [224, 225]. US is also becoming widely used for superficial tissue evaluation (skin and subdermis) in children with scleroderma and dermatomyositis. However, US is limited in the assessment of deeper lesions and the ones proximal to the airway, gastrointestinal tract, and skeletal structures [222]. Unlike in adults, to date, the use of imaging for research purposes has been scarce in children, mainly due to the limited standardization of imaging techniques and the paucity of validation studies.

This chapter will focus on the role of MSUS in diagnosing and monitoring several pediatric musculoskeletal disorders, excepting DDH. Today's standards of hip US in DDH are well established. The Graf's (morphological/static) and Harcke's (dynamic) methods have been the focus of ongoing development as a result of using US screening for the past 30 years [226].

\subsection{Normal sonoanatomy of the musculoskeletal system}

\section{Clinical applications}

Several studies in children provided relevant information of ageand gender-specific sonoanatomy crucial for pathology recognition. Two of them addressed the development of definitions for the US appearance of joints (i. e., hyaline cartilage, epiphyseal secondary ossification center, joint capsule, normal synovial membrane, the ossified portion of articular bone, physiological vascularity, and the fat pad tissue) in healthy children through a consensus process and validation in several practical exercises [219, 220].

A small amount of physiologic fluid located at several joint recesses and the finger flexor tendon sheaths has been described on B-mode US. This was particularly evident in the suprapatellar recess (around $60 \%$ ) [227-230].

Several studies reported that the joint cartilage thickness (JCT) shows a steady decline with age [230-235] and it seems to be significantly greater in boys than in girls in peripheral joints [231, 232]. Conversely, Samanta et al. did not find any significant difference at the wrist joint [233]. Intra- and inter-observer variations in JCT measurement have been documented as acceptable in several studies [230, 234, 235]. A strong association between the mean tendon thickness of lower limbs and age has been reported $(p \leq 0.001)$ [226, 236, 237].

Several studies reported on physiological vascularity using the Doppler technique, mainly detected at physeal and epiphyseal cartilaginous structures in joints and entheses [220, 227, 236, 237]. Chauvin et al. documented the Doppler signal at asymptomatic sites in two locations: 1 ) peri-entheseal (1-3 color spots displayed) in peripubertal children and 2) intra-entheseal in the quadriceps tendon in younger children (4-9y. o.) [227]. Roth et al. found similar results [236], whereas Jousse-joulin et al. did not find US vascularity in any of the healthy entheses evaluated [237].

\section{Statement}

1. US is able to show children's age-related variations in the sonoanatomy of healthy joints and tendons (LOE 4). Broad consensus (23/7/6, 77\%)

\subsection{Inflammatory arthritis}

JIA represents the most common rheumatic disorder in childhood. Consensus-based recommendations on the use of imaging in JIA were recently published [223].

\section{Clinical applications}

The diagnosis of JIA is mainly based on clinical features and the exclusion of other conditions mimicking chronic arthritis. US has the potential role to narrow the differential diagnosis [223, 238].

US has a better sensitivity than clinical examination for the detection of inflammation in peripheral, particularly small joints [239-246]. US allows precise identification of the structures affected by the inflammatory process (joint, tendon, enthesis) with implication for JIA classification, extension, and treatment strategy (including US-guided local treatment) [225, 237]. US is sensitive for tracking treatment-induced synovial changes [225]. Lanni et al. reported a strong sensitivity to change for grayscale and power Doppler US scores (standardized response mean 2.44 and 1.23), suggesting their potential use as outcome measures [247].

Standardized US examination protocols for the JIA are currently available [248]. A reduced 10-joint US assessment has been proposed as it was found to be as valid and feasible as the 44-joint comprehensive US evaluation [249].

Studies comparing US with MRI have shown a poor sensitivity of US for the early detection of temporomandibular joint involvement $[250,251]$.

US studies have demonstrated persistent synovitis in a significant proportion of JIA patients with "clinically inactive disease" [252-255]. Pilot studies found that US-detected synovial abnormalities did not predict disease flare in clinically inactive JIA [252, 256, 257]. Conversely, De Lucia et al. showed an increased risk of flare $(\mathrm{OR}=3.8,95 \% \mathrm{Cl} 1.2$ to 11.5$)$ [253], and Silva's et al. study reported similar results [254]. Although US offers a more accurate evaluation of remission status over clinical examination, the prognostic value of subclinical synovitis is still being defined.

US has the potential to enhance the detection of structural damage over clinical examination and conventional radiography [258-261]. When comparing US with radiography, the same detection rate has been described in wrist erosive changes for both methods [258] and 1.4-fold in the assessment of knee joint space narrowing [260]. Evidence that US is a reliable tool for the assessment of cartilage damage in JIA has been supported by the excellent agreement achieved between MRI and US measurements of the distal femoral cartilage thickness [169].

\section{Recommendation}

1. US is more sensitive than clinical examination in the evaluation of inflamed joints. This technique should be integrated into clinical examination in a child with recent-onset inflammatory 
arthritis to improve diagnosis of JIA (LoE 2, SoR strong). Strong consensus $(32 / 1 / 3,97 \%)$

2. US has demonstrated high sensitivity to show inflammatory changes and might be considered for monitoring joint inflammation in JIA patients (LoE 3, SoR weak). Strong consensus (32/0/4, $100 \%)$

3. US might be used to detect subclinical synovitis in JIA patients in clinical remission (LoE 3, SoR weak). Strong consensus (34/0/2, $100 \%)$

\subsection{Infections}

\section{Clinical applications}

US is useful for the early diagnosis of pediatric septic arthritis (SA), particularly in the hip joint. US shows high sensitivity and low specificity [261-264]. US features, such as predominant synovial (capsular) thickening associated with increasing joint effusion, high fever, and high serum CRP level are predictive of hip SA [265]. Two studies identified US as being the imaging technique of choice in the initial workup of the pediatric irritable hip or transient synovitis [265, 266].

\section{Recommendation}

1. When septic arthritis is clinically suspected, US can visualize the presence of joint effusion and guide fluid aspiration. However, differentiation between septic arthritis, transient synovitis, and early osteomyelitis is not possible based on US findings alone (LoE 4, SoR). Broad consensus (26/5/5, $84 \%$ )

\subsection{Overload syndromes}

Osgood-Schlatter disease (OSD), Sinding-Larsen-Johansson syndrome (SLJS), and jumper's knee syndrome are enthesopathies affecting the adolescent knee joint and usually have a good prognosis. The classic US findings associated with overload syndromes in the knee are: a hypoechoic/anechoic region in the enthesis, with or without thickening, tears, vascularity, and bone lesions, including fragmentation of the tibial tubercle ossification center (OSD) or the distal patellar pole (SLJS).

\section{Clinical applications}

OSD seems to be associated with the degree of bone maturation. Kaneuchi et al. showed that the risk of OSD significantly increased from the cartilaginous stage - unossified tibial tuberosity (TbT) to the secondary ossification center stage $(O R=9.48)$ [266]. In addition to morphological changes in OSD, Doppler signal surrounding the TbT apophysis was detected along with knee pain (within the enthesis, bursa, and the Hoffa fat pad) [267]. Of note, the classic US findings in OSD have also been found in young athletes without symptoms [268, 269].

\section{Recommendation}

1. US might be considered a first-line imaging diagnostic technique in overload syndromes of the knee in adolescents (LoE 3b, SoR weak). Broad consensus (25/7/4, 78\%)

\subsection{Pediatric Trauma}

\section{Clinical applications}

US provides an alternative to conventional radiography in the investigation of pediatric trauma [270]. In extremity fractures (mainly humerus and forearm), the sensitivity, specificity, positive predictive value (PPV), and negative predictive values (NPV) for US were high [270, 271]. The agreement between radiography and US to detect fractures was reported in $93 \%$ of cases. It was higher for the femur, nasal bones, and ribs/sternum (100\%), and lower for the bones of the hands and feet (75\%) [272].

In the detection of pediatric elbow fractures, a meta-analysis has showed a summary sensitivity of $96 \%$ and specificity of $89 \%$ and a pooled proportion of false-negative rate of $3.7 \%$ for US [273]. For supracondylar fractures of the distal humerus (SCFs) US diagnosis in comparison to radiography showed a sensitivity, specificity, NPV, and PPV of $100 \%, 93.5 \%, 100 \%$, 95.2\%, respectively [274]. The presence of the posterior/dorsal fat pad sign (dFPS) predicted an elbow fracture with a sensitivity and specificity just under $100 \%$ and a PPV of $90.2 \%$ with an NPV of $97.4 \%$ $[275,276]$. Similar values of sensitivity and specificity were obtained in the detection of hand and foot bony fractures [277, 278]

A meta-analysis on occult ankle fractures in children with suspicious symptoms showed that the operating characteristic for US ranged in positive likelihood ratio from 9 to 20 and in negative likelihood ratio from 0.04 to 0.08 [279]. US is more sensitive than radiography (100 vs. $40 \%$ ) for the diagnosis of avulsion fractures of the anterior talofibular ligament which require urgent diagnosis and orthopedic consultation [280].

The US sensitivity and specificity values for the diagnosis of pediatric nasal bone and skull fractures were variable. They seem to be higher in children younger than 2 years old [281, 282].

US was used in the diagnosis and monitoring of congenital muscular torticollis [283].

US findings are often nonspecific in post-traumatic myositis ossificans [284].

\section{Recommendation}

1. US might be used in children with clinically suspected fractures to guide the diagnostic process (LoE 3, SoR weak). Broad consensus $(30 / 3 / 3,91 \%)$

2. US might be used as a screening tool for the evaluation of suspected elbow fractures (LoE 3, SoR weak) Broad consensus $(24 / 4 / 8,86 \%)$

\subsection{Pediatric vascular anomalies}

\section{Clinical applications}

Infantile hemangioma is the most common benign tumor in children. Clinical presentation and typical grayscale and Doppler US features may confirm the diagnosis of superficial soft-tissue hemangioma, thereby avoiding biopsies [221, 285-290]. Conversely, atypical and deep-seated hemangiomas show no specific US findings [287-299].

Several studies report distinct US images for other lesions, such as congenital hemangioma [221, 292], locally aggressive tu- 
mors, such as Kaposiform hemangioendothelioma [293], vascular malformations (capillaries, venous, lymphatic, and arteriovenous, or high-flow and low-flow lesions) and fibro-adipose vascular anomaly (FAVA) [221, 285, 288, 289, 294, 295].

\section{Recommendation}

1. US might be used as a first-line examination in the diagnosis of small and superficial vascular anomalies (LoE 5, SoR weak).

Broad consensus (25/5/6, $83 \%)$

\subsection{US of spine in children}

Spinal US is an ideal imaging technique for a preliminary workup of the spine in newborns and young children [296] and is used in the diagnosis of occult and non-occult spinal dysraphism and in the assessment of spinal cord abnormalities, vascular malformations, and birth-related trauma of the spine [297-301].

\section{Clinical applications}

US is the first-line imaging technique for the assessment of the spine and its content in the youngest children [296-304]. During the first 3-6 months of life, the incompletely ossified posterior vertebral arch offers a valuable acoustic window to spinal US. US allows an accurate depiction of neural structures in the spinal canal [305]. However, MRI remains the first-line technique in older children when ossification of the posterior arch is complete [306].

Newborns should undergo spinal US evaluation in the following circumstances: posterior midline cutaneous markers (midline or paramedian back masses or dimples higher than the intergluteal fold especially when associated with midline skin discoloration, skin tags, hair tufts, hemangiomas), foot abnormalities, anorectal and genitourinary malformations and neurologically abnormal lower limbs, spina bifida occulta, tethered cord, intracanal masses, raphe dysraphism including myelomeningocele, myeloceles [296-304]. Nevertheless, the diagnosis should ultimately be confirmed and characterized by MRI.

Spinal US guides interventional procedures [307] and assesses complications of spinal tap [308, 309]. In addition, spinal US can provide an accurate measurement of the lengthening of magnetically controlled growing spinal rods $[310,311]$ and can show the Cobb angle changes of adolescents with scoliosis during follow-up [312].

M-mode US reveals oscillations of the cord due to respiration and the cardiac cycle [312]. The lack of movement of the terminal cord is an ancillary US sign of tethered cord [296, 300]. Color Doppler US displays the epidural venous plexus as well as the central branches of the anterior spinal artery [313]. New three-dimensional US probes and post-processing software offer a valuable opportunity to create multiplanar reconstructed images [314, 315].

The feasibility and reliability of intervertebral disc shear-wave elastography suggests it should be used as a routine tool for the early detection and monitoring of the progression of vertebral disc abnormalities [316].

Of note, normal variants mimicking spinal pathology such as ventriculus terminalis and transient dilatation of the central canal, pilar cyst, pseudo-sinus tract, and thick filum terminale $(<2 \mathrm{~mm})$
[317, 318] should be taken into account. Additionally, a false image of duplication of the spinal cord is a common artifact to consider when looking for spinal cord duplication [318].

Isolated sacral dimples of the intergluteal fold do not predict underlying spinal cord malformations, and spinal US should not be performed in neonates with simple sacral dimples [318].

Practical points, limitations, and artifacts in pediatric applications are detailed in Supplementary Tables $\mathbf{1}$ and $\mathbf{2}$.

\section{Recommendation}

1. For spine evaluation in newborns up to the age of 3-4 months, US should be used as a first-line tool (LoE 1a, SoR strong).

Broad consensus (27/2/7, $93 \%$ )

\section{MSUS-guided procedures}

\subsection{Arthrocentesis and therapeutic injections}

\section{Background}

Over the past 20 years, US-guided intra-articular (IA) and peri-articular (PA) diagnostic and therapeutic injections have earned their place in clinical practice. The use of US to direct the needle improves accuracy, performance, and safety by facilitating visualization of the target area avoiding damage to vulnerable tissues such as nerves, vessels, tendons, ligaments and cartilage. In addition, US scan prior to injection enables a point-of-care morphopathologic assessment of the problem. US-guided injections can be performed indirectly (pre-recorded visualization) or directly either free-hand or with device guidance. US-guided musculoskeletal injections are typically performed free-hand with real-time visualization.

\section{Clinical application}

US-guided arthrocentesis and IA injections are more accurate than anatomical palpatory landmarks for fluid aspiration or for delivering drugs in many superficial, deep, large, and small joints [319-328]. Glucocorticoids (GC) and hyaluronic acid (HA) are currently the most frequent IA injectables used in clinical practice. However, whether US-guided IA injections improve efficacy warrants further investigation [323, 325, 327, 328]. Since 1952, GC have been injected into joints to decrease local joint synovial inflammatory response and pain in patients with inflammatory and degenerative arthritis [329, 330]. Data comparing the efficacy and safety of the different available preparations is limited [330]. Crystalline long-acting GC (methylprednisolone acetate, triamcinolone acetonide, and triamcinolone hexacetonide) preparations are commonly used because they are taken up by the synovial lining cells allowing continued local release plus small systemic absorption [330]. IA HA preparations relieve pain and can improve function in osteoarthritic joints by restoring the elastic and viscous properties of the synovial fluid [331, 332]. They have also been used in adhesive shoulder capsulitis [333, 334]. Those compounds with higher molecular weight and obtained from biological fermentation process seem to offer a better efficacy and safety profile [335]. 
US-guided PA injections have continued to develop and expand, and multiple therapeutic options have become available, all with varying levels of supportive clinical evidence of their efficacy. US-guided intra-tenosynovial GC injections are more accurate, safer, and are more effective than palpatory GC injections for treating inflammatory tenosynovitis [336, 337]. When needed for diagnostic purposes, very small amounts of tenosynovial fluid can be easily aspirated using US guidance [338]. US-guided GC intra-bursal injection is effective and safe for treating refractory Achilles enthesitis in patients with SpA [339]. Intratendinous USguided injectables, such as dextrose, high-volume saline, plateletrich plasma, are used to treat chronic tendinopathies. However, there is no evidence whether US guidance is more effective and/ or safer than conventional blinded intratendinous injections [340-352].

Finally, several studies have shown good feasibility for US-guided pararadicular and facet joint injections at the cervical/lumbar spine [353-355] and superior sacroiliac joints [356].

Practical points, limitations, and artifacts in arthrocentesis and therapeutic injections are detailed in Supplementary Tables 1 and 2.

\section{Recommendations}

1. US guidance should be considered for fluid aspiration (LoE 1, SoR strong). Strong consensus (34/0/2, $100 \%)$

2. US guidance should be considered to improve the accuracy of intraarticular injections (LoE 1b, SoR strong). Strong consensus (34/0/2, $100 \%)$

3. US guidance should be used in intra-tenosynovial glucocorticoid injection for inflammatory tenosynovitis (LoE 1b, SoR strong). Strong consensus (34/0/2, $100 \%)$

4. US-guided procedures such as high-volume injection in painful Achilles chronic tendinopathy and platelet-rich plasma in plantar fasciitis, patellar tendinopathy, and epicondylitis might be considered (LoE 2b, SoR weak). Broad consensus (31/3/2, $91 \%$ )

5. US-guided therapeutic injections of the cervical/lumbar spine and $\mathrm{SI}$ joints might be considered as an alternative for CT or fluoroscopy guidance (LoE 2, SoR weak). Broad consensus $(29 / 4 / 3,88 \%)$

\subsection{Musculoskeletal biopsy}

\section{Background}

Synovial biopsies are performed commonly for clinical purposes or translational research [357-359]. Synovial tissue samples are taken from joints or tendon sheaths in order to perform cellular and molecular analysis. US guidance is widely used in order to guide the biopsy needle or forceps into the biopsy area (joint synovitis, tenosynovitis), but other techniques exist, especially arthroscopic guidance [360].

It is important to determine the biologic potential of soft-tissue tumors before surgery, due to the impact on patient management and prognosis [361-363]. This often requires histologic confirmation [363, 364]. Percutaneous core needle biopsy (PCNB) of muscle and soft tissue tumors is often performed under US guidance $[365,366]$ and contrast-enhanced US can be consid- ered for guiding the biopsy in significant areas (vascularized areas) of the tumors [367, 368].

\section{Clinical application}

Sampling of synovial tissue or tendon sheaths can be very useful in the clinical context of suspicion of joint infection while making it possible to perform histological and bacteriological analyses. In published case series and cohorts, synovial and tendon biopsy allowed a definite diagnosis in $16.2 \%$ of cases [358] and had a direct diagnostic impact in $37 \%$ of cases, with a positive predictive value of $100 \%$ and a negative predictive value of $95 \%$ for infection [359].

PCNB of soft-tissue tumors is more cost-effective and less invasive compared with biopsy, has lower complication rates, and provides comparable yield rates [362, 369-371].

Practical points, limitations, and artifacts in musculoskeletal biopsy are detailed in Supplementary Tables $\mathbf{1}$ and $\mathbf{2}$.

\section{Recommendation}

1. US-guided synovial biopsies can be performed safely and might be helpful in the clinical setting for the diagnosis of joint infection when synovial fluid analysis is not available or is nonconclusive (LoE 3, SoR weak). Strong consensus (32/1/3, $97 \%$ )

2. US-guided core needle biopsy of soft-tissue tumors must be done along the planned surgery incision in collaboration with the orthopedic oncologist, obtaining at least four specimens, each with a length of more than $10 \mathrm{~mm}$. The target must be viable tumor regions. Unaffected compartments or neurovascular bundles must not be contaminated by the biopsy tract

(LoE 2, SoR strong). Strong consensus (33/1/2, $97 \%$ )

\subsection{Perineural injection}

\section{Background}

Perineural injections (nerve blocks) are performed routinely by anesthetists and pain specialists to block nerve conduction to/ from an affected area.

Nerve blocks encompass both central: neuraxial blocks (spinal, epidural, combined spinal-epidural, paravertebral) - outside the scope of this body of work - and peripheral: plexus and terminal nerve blocks. The technique is applicable to individual anatomical locations [372]. The strategy of selection of the optimal block for a specific surgical procedure is "as distal as possible and as proximal as necessary" [373].

\section{Clinical application}

Perineural injections aim at depositing local anesthetics with or without additives (epinephrine, steroids, alpha2 agonists, etc.) in the vicinity of a plexus or nerve with the goal of achieving analgesia or complete surgical anesthesia (thus rendering an area insensate allowing surgery and obviating the need for general anesthesia). Historically, various other nerve localization modalities have been employed, such as paresthesia, anatomical landmarks, peripheral nerve stimulators, loss of resistance ('pops'), and trans-arterial techniques. 
US-guided nerve hydrodissection using local anesthetics, saline, $5 \%$ dextrose, glucocorticoids, hyaluronidase, or platelet-rich plasma, has recently emerged as a potential minimally invasive non-surgical treatment for nerve entrapment syndromes [374].

US guidance has been shown to increase the efficacy of perineural injections due to more precise injectate deposition, as quantified by more blocks deemed sufficient for surgery following sensory or motor testing and fewer blocks requiring supplementation or conversion to general anesthesia [375-378]. Also, it improves their safety profile by reducing, although not eliminating, the incidence of nerve injury and inadvertent intravascular injections. While the fewer needle passes do not translate into fewer postoperative neurologic symptoms [379], US is effective in reducing local anesthetic systemic toxicity across its clinical presentation continuum [380].

In addition, US appears to hasten block performance and onset time of peripheral nerve blocks, especially in the lower extremity [376-378].

Practical points, limitations, and artifacts in perineural injections are detailed in Supplementary Tables 1 and 2.

\section{Recommendations}

1. Real-time US guidance should be considered for perineural injections (LoE 1, SoR strong). Strong consensus (34/0/2, 100\%)

2. US monitoring of the needle tip should be performed throughout the injection in order to avoid intraneural needle tip placement (LoE 2, SoR strong). Strong consensus (30/1/5, $97 \%$ )

3. US visualization of tissue expansion/injectate spread without resultant increase of the cross-sectional area of the nerve should be sought (LoE 2, SoR strong). Strong consensus $(29 / 0 / 7,100 \%)$

\section{Conclusion}

In conclusion, this international multidisciplinary task force has produced, under the auspices of EFSUMB, an evidence-based comprehensive update on clinical applications of MSUS as well as consensus-based recommendations in the field. We expect this EFSUMB product to be useful to the MSUS community.

\section{Conflict of interest}

Fernando Alfageme Speaker honoraria: GE, Mindray; Equipment support: Esaote

David Bong No Conflicts of interest

Angel Bueno No Conflicts of interest

Vito Cantisani Speaker honoraria: Bracco, Samsung, Canon

Paz Collado No Conflicts of interest

Maria Antonietta D'Agostino No Conflicts of interest

Daniela Fodor No Conflicts of interest

Javier de la Fuente No Conflicts of interest

Wolfgang Hartung Speaker honoraria: Abbvie, GE Healthcare, Alpinion Medical; Ultrasound equipment support; Alpinion Medical Germany,

Canon Medical Germany

Hilde Hammer Speake honoraria and/or consultancy; AbbVie, Lilly,

Roche, Novartis

Andrea Klauser No Conflicts of interest
Jens Kessler No Conflicts of interest Manuela Lenghel No Conflicts of interest Carlo Martinoli Speaker honoraria and equipment support: Philips, Canon Dolores Mendoza-Cembranos No Conflicts of interest Mihaela Micu No Conflicts of interest Ingrid Möller No Conflicts of interest Aurelie Najm No Conflicts of interest Gabriella lohom No Conflicts of interest Clara Malattia No Conflicts of interest Peter Mandl No Conflicts of interest Esperanza Naredo No Conflicts of interest Levent Ozcakar No Conflicts of interest Riccardo Picasso No Conflicts of interest Athena Plagou Speaker honoraria: GE Sebastian C Rodriguez-Garcia No Conflicts of interest Xavier Sala-Blanch No Conflicts of interest Luca Scofienza Non-financial support: Samsung Imaging, Abiogen, Bracco Imaging Italia; Speaker honoraria: Esaote SPA, Abiogen, Biolive, Fidia Pharma Group, Novartis, Pfizer Oana Serban No Conflicts of interest Paolo Simoni No Conflicts of interest Iwona Sudoł-Szopińska No Conflicts of interest Lene Terslev Speaker honoraria: GE Christian Tesch No Conflicts of interest Plamen Todorov No Conflicts of interest Jacqueline Uson No Conflicts of interest Violeta Vlad No Conflicts of interest Federico Zaottini No Conflicts of interest Michael Pelea, Diana Bilous, Anamaria Marian, Roxana Gutiu No conflict of interest.

\section{Acknowledgements}

The authors thanks Lynne Rudd, Daniele Fresilli and Patrizia Pacini for all the support.

\section{References}

[1] Luukkainen R, Sanila MT, Luukkainen P. Poor relationship between joint swelling detected on physical examination and effusion diagnosed by ultrasonography in glenohumeral joints in patients with rheumatoid arthritis. Clin Rheumatol 2007; 26: 865-867

[2] Amin MF, Ismail FM, El Sherref RR. The role of Ultrasonography in early detection and monitoring of shoulder erosions and disease activity in rheumatoid arthritis patients; comparison with MRI examination. Acad Radiol 2012; 19: 693-700

[3] Stegbauer J, Rump LC, Weiner SM. Sites of inflammation in painful shoulder assessed by musculoskeletal ultrasound and Power Doppler sonography. Rheumatol Int 2008; 28: 459-465

[4] Ruta S, Rosa J, Navarta DA et al. Ultrasound assessment of new onset bilateral painful shoulder in patients with polymyalgia reumatica and rheumatoid arthritis. Clin Rheumatol 2012; 31: 1383-1387

[5] Ottaviani S, Gill G, Palazzo E et al. Ultrasonography of shoulders in spondyloarthritis and rheumatoid arthritis- a case control study. Joint Bone Spine 2014; 81: 247-249

[6] Girish G, Lobo LG, Jacobson JA et al. Ultrasound of the shoulder: asymptomatic findings in men. Am J Roentgenol 2011; 197: W713-W719

[7] Naredo E, Aguado P, De Miguel E et al. Painful shoulder: comparison of physical examination and ultrasonographic findings. Ann Rheum Dis 2002; 61: 132-136

[8] Levine BD, Motamedi K, Seeger LL. Imaging of the shoulder: a comparison of MRI and Ultrasound. Curr Sports Med Rep 2012; 11: 239-243 
[9] Strunk ], Lange U, Kurten B et al. Doppler sonographic findings in the long bicipital tendon sheaths in patients with rheumatoid arthritis as compared with patients with degenerative diseases of the shoulder. Arthritis Rheum 2003; 48: 1828-1832

[10] Bruyn GAW, Naredo E, Moller I et al. Reliability of ultrasonography in detecting shoulder disease in patients with rheumatoid arthritis. Ann Rheum Dis 2009; 68: 357-361

[11] Okoroha KR, Mehran N, Duncan J et al. Characterization of Rotator Cuff Tears: Ultrasound Versus Magnetic Resonance Imaging. Orthopedics 2017; 40: e124-e130

[12] Rutten M], Spaargaren G], van Loon T et al. Detection of rotator cuff tears: the value of MRI following ultrasound. Eur Radiol 2010; 20: 450 457

[13] de Jesus JO, Parker L, Frangos AJ et al. Accuracy of MRI, MR arthrography, and ultrasound in the diagnosis of rotator cuff tears: a meta-analysis. Am J Roentgenol 2009; 192: 1701-1707

[14] Elmorsy A, Keightley A, Flannery M. Accuracy of Ultrasonography (US) and Magnetic Resonance Imaging (MRI) in Detection of Rotator Cuff Tears in District General Hospital. Pol J Radiol 2017; 82: 634-637

[15] Gilat R, Atoun E, Cohen O et al. Recurrent rotator cuff tear: is ultrasound imaging reliable? J Shoulder Elbow Surg 2018; 27: 1263-1267

[16] Teefey SA, Rubin DA, Middleton WD et al. Detection and quantification of rotator cuff tears. Comparison of ultrasonographic, magnetic resonance imaging, and arthroscopic findings in seventy-one consecutive cases. J Bone Joint Surg Am 2004; 86: 708-716

[17] Ingwersen KG, Hjarbaek J, Eshoej $\mathrm{H}$ et al. Ultrasound assessment for grading structural tendon changes in supraspinatus tendinopathy: an inter-rater reliability study. BMJ Open 2016; 6: e011746

[18] Arend CF, Arend AA, da Silva TR. Diagnostic value of tendon thickness and structure in the sonographic diagnosis of supraspinatus tendinopathy: room for a two-step approach. Eur J Radiol 2014; 83: 975-979

[19] Park GY, Park JH, Kwon DR et al. Do the Findings of Magnetic Resonance Imaging, Arthrography, and Ultrasonography Reflect Clinical Impairment in Patients With Idiopathic Adhesive Capsulitis of the Shoulder? Arch Phys Med Rehabil 2017; 98: 1995-2001

[20] Kim DH, Cho CH, Sung DH. Ultrasound measurements of axillary recess capsule thickness in unilateral frozen shoulder: study of correlation with MRI measurements. Skeletal Radiol 2018; 47: 1491-1497

[21] Ahn KS, Kang CH, Jeong WK. Contrast-Enhanced Ultrasonography in Patients with Adhesive Capsulitis: Preliminary Experience. Iran J Radiol 2017; 14: e33069

[22] Kim DH, Choi YH, Oh S et al. Ultrasound Microflow Imaging Technology for Diagnosis of Adhesive Capsulitis of the Shoulder. J Ultrasound Med 2020; 39: 967-976

[23] Homsi C, Bordalo-Rodrigues M, da Silva J] et al. Ultrasound in adhesive capsulitis of the shoulder: is assessment of the coracohumeral ligament a valuable diagnostic tool? Skeletal Radiol 2006; 35: 673-678

[24] Michelin P, Delarue Y, Duparc F et al. Thickening of the inferior glenohumeral capsule: an ultrasound sign for shoulder capsular contracture. Eur Radiol 2013; 23: 2802-2806

[25] Kim I, Yi JH, Lee J et al. Limited subacromial gliding of the supraspinatus tendon during dynamicdynamic ultrasonography can predict a decrease in capacity and MR arthrographic features of the shoulder joint. Eur Radiol 2012; 22: 2365-2370

[26] Martinoli C, Bianchi S, Prato $\mathrm{N}$ et al. US of the shoulder: non-rotator cuff disorders. Radiographics 2003; 23: 381-401

[27] Pavic R, Margetic P, Bensic M et al. Diagnostic value of US, MR and MR arthrography in shoulder instability. Injury 2013; 44 (Suppl. 3): S26-S32

[28] Gottlieb M, Holladay D, Peksa GD. Point-of-care ultrasound for the diagnosis of shoulder dislocation: A systematic review and meta-analysis. Am J Emerg Med 2019; 37: 757-761
[29] Magnusson L, Kälebo P, Baranto A et al. The value of ultrasonography in the preoperative diagnostic evaluation of patients with recurrent anterior shoulder dislocation: a prospective study of 44 patients. Knee Surg Sports Traumatol Arthrosc 2007; 15: 649-653

[30] Merolla G, Paladini P, Di Napoli G et al. Outcomes of arthroscopic Hill-Sachs remplissage and anterior Bankart repair: a retrospective controlled study including ultrasound evaluation of posterior capsulotenodesis and infraspinatus strength assessment. Am J Sports Med 2015; 43: 407-414

[31] Gottlieb M, Russell F. Diagnostic Accuracy of Ultrasound for Identifying Shoulder Dislocations and Reductions: A Systematic Review of the Literature. West J Emerg Med 2017; 18: 937-942

[32] Cheng SC, Hulse D, Fairbairn KJ et al. Comparison of dynamic ultrasound and stress radiology for assessment of inferior glenohumeral laxity in asymptomatic shoulders. Skeletal Radiol 2008; 37: 161-168

[33] Cheng SC, Sivardeen ZK, Wallace WA et al. Shoulder instability in professional rugby players-the significance of shoulder laxity. Clin J Sport Med 2012; 22: 397-402

[34] Nazarian LN. The top 10 reasons musculoskeletal sonography is an important complementary or alternative technique to MRI. Am J Roentgenol 2008; 190: 1621-1626

[35] De Maeseneer M, Jacobson JA, Jaovisidha $S$ et al. Elbow effusions: distribution of joint fluid with flexion and extension and imaging implications. Invest Radiol 1998; 33: 117-125

[36] Finlay K, Ferri M, Friedman L. Ultrasound of the elbow. Skeletal Radiol 2004; 33: 63-79

[37] Luukkainen R, Sanila MT, Saltyshev M et al. Relationship between clinically detected joint swellin and effusion diagnosed by ultrasonography in elbow joints in patients with rheumatoid arthritis. Clin Rheumatol 2005; 24: 228-231

[38] Koski JM. Ultrasonography of the elbow joint. Rheumatol Int 1990; 10: 91-94

[39] Lerch K, Borisch N, Paetzel C et al. Sonographic evaluation of the elbow in rheumatoid arthritis: a classification of joint destruction. Ultrasound Med Biol 2003; 29: 1131-1135

[40] Lerch K, Borisch N, Paetzel C et al. Proposal for a sonographic classification of target joints in rheumatoid arthritis. Rheumatol Int 2005; 25 : 215-219

[41] Celikyay F, Inanir A, Bilgic E et al. Ultrasonographic evaluation of the posterolateral radiohumeral plica in asymptomatic subjects and in patients with osteoarthritis. Med Ultrason 2015; 17: 155-159

[42] Konin GP, Nazarian LN, Walz DM. US of the elbow: indications, technique, normal anatomy, and pathologic conditions. Radiographics 2013; 33: E125-E147

[43] Martinoli C, Bianchi S, Giovagnorio F et al. Ultrasound of the elbow. Skeletal Radiol 2001; 30: 605-614

[44] Bruns J, Lüssenhop S. Ultrasound imaging of the elbow joint. Loose bodies and osteochondrosis dissecans. Ultraschall in Med 1993; 14: 5862

[45] DeMoss A, Millard N, Mcllvain G et al. Ultrasound-Assisted Assessment of Medial Elbow Stability. J Ultrasound Med 2018; 37: 2769-2775

[46] Shanley E, Smith M, Mayer BK et al. Using Stress Ultrasonography to Understand the Risk of UCL Injury Among Professional Baseball Pitchers Based on Ligament Morphology and Dynamic Abnormalities. Orthop J Sports Med 2018; 6: 2325967118788847

[47] Nazarian LN, McShane JM, Ciccotti MG et al. Dynamic US of the anterior band of the ulnar collateral ligament of the elbow in asymptomatic major league baseball pitchers. Radiology 2003; 227: 149-154

[48] Park JY, Kim H, Lee JH et al. Valgus stress ultrasound for medial ulnar collateral ligament injuries in athletes: is ultrasound alone enough for diagnosis? J Shoulder Elbow Surg 2020; 29: 578-586 
[49] Ciccotti MG, Atanda AJr, Nazarian LN et al. Stress Sonography of the Ulnar Collateral Ligament of the Elbow in Professional Baseball Pitchers A 10-Year Study. Am J Sports Med 2014; 42: 544-551

[50] Sasaki ], Takahara M, Ogino T et al. Ultrasonographic assessment of the ulnar collateral ligament and medial elbow laxity in college baseball players. J Bone Joint Surg Am 2002; 84: 525-531

[51] Schmidt WA, Schmidt H, Schicke B et al. Standard reference values for musculoskeletal ultrasonography. Ann Rheum Dis 2004; 63: 988-994

[52] Vlad V, Berghea F, Libianu S et al. Ultrasound in rheumatoid arthritis volar versus dorsal synovitis evaluation and scoring. BMC Musculoskelet Disorders 2011; 12: 124

[53] Chiavaras MM, Jacobson JA, Yablon CM et al. Pitfalls in wrist and hand ultrasound. Am J Roentgenol 2014; 203: 531-540

[54] Terslev L, Naredo E, Aegerter P et al. Scoring ultrasound synovitis in rheumatoid arthritis: a EULAR-OMERACT ultrasound taskforce-Part 2: reliability and application to multiple joints of a standardised consensusbased scoring system. RMD Open 2017; 3: e000427

[55] Andersen M, Ellegaard K, Hebsgaard JB et al. Ultrasound colour Doppler is associated with synovial pathology in biopsies from hand joints in rheumatoid arthritis patients: a cross-sectional study. Ann Rheum Dis 2014; 73: 678-683

[56] Just SA, Nielsen C, Werlinrud JC et al. Six-month prospective trial in early and long-standing rheumatoid arthritis: evaluating disease activity in the wrist through sequential synovial histopathological analysis, RAMRIS magnetic resonance score and EULAR-OMERACT ultrasound score. RMD Open 2019; 5: e000951

[57] Hammer HB, Bolton-King P, Bakkeheim V et al. Examination of intra and interrater reliability with a new ultrasonographic reference atlas for scoring of synovitis in patients with rheumatoid arthritis. Ann Rheum Dis 2011; 70: 1995-1998

[58] Vlad V, Berghea F, lagnocco A et al. Inter \& Intra-Observer Reliability Of Grading Ultrasound Videoclips With Hand Pathology In Rheumatoid Arthritis By Using Non- Sophisticated Internet Tools (LUMINA Study). Med Ultrason 2014; 16: 32-36

[59] Klauser A, Frauscher F, Schirmer M et al. The value of contrast-enhanced color Doppler ultrasound in the detection of vascularization of finger joints in patients with rheumatoid arthritis. Arthritis Rheum 2002; 46: 647-653

[60] Klauser AS, Franz M, Bellmann Weiler R et al. Contrast-enhanced ultrasonography for the detection of joint vascularity in arthritis-subjective grading versus computer-aided objective quantification. Ultraschall in Med 2011; 32 (Suppl. 2): E31-E37

[61] Klauser A, Frauscher F, Halpern E] et al. Remitting seronegative symmetrical synovitis with pitting edema of the hands: ultrasound, color doppler ultrasound, and magnetic resonance imaging findings. Arthritis Rheum 2005; 53: 226-233

[62] Klauser A, Demharter ], De Marchi A et al. Contrast enhanced gray-scale sonography in assessment of joint vascularity in rheumatoid arthritis: results from the IACUS study group. IACUS study group. Eur Radiol 2005; 15: 2404-2410

[63] Mandl P, Supp G, Baksa G et al. Relationship between radiographic joint space narrowing, sonographic cartilage thickness and anatomy in rheumatoid arthritis and control joints. Ann Rheum Dis 2015; 74: 2022-2027

[64] Klauser AS, Halpern E], Strobl S et al. Gout of hand and wrist: the value of US as compared with DECT. Eur Radiol 2018; 28: 4174-4181

[65] Finzel S, Ohrndorf S, Englbrecht M et al. A detailed comparative study of high-resolution ultrasound and micro-computed tomography for detection of arthritic bone erosions. Arthritis Rheum 2011; 63: 1231-1236

[66] Dohn UM, Terslev L, Szkudlarek M et al. Detection, scoring and volume assessment of bone erosions by ultrasonography in rheumatoid arthritis: comparison with CT. Ann Rheum Dis 2013; 72: 530-534
[67] Brown AK, Quinn MA, Karim Z et al. Presence of significant synovitis in rheumatoid arthritis patients with disease modifying antirheumatic drug-induced clinical remission: evidence from an imaging study may explain structural progression. Arthritis Rheum 2006; 54: 3761-3773

[68] Brown AK, Conaghan PG, Karim Z et al. An explanation for the apparent dissociation between clinical remission and continued structural deterioration in rheumatoid arthritis. Arthritis Rheum 2008; 58: 2958-2967

[69] Saleem B, Brown AK, Quinn M et al. Can flare be predicted in DMARD treated RA patients in remission, and is it important? A cohort study. Ann Rheum Dis 2012; 71: 1316-1321

[70] Wakefield RJ, Gibbon WW, Conaghan PG et al. The value of sonography in the detection of bone erosions in patients with rheumatoid arthritis: a comparison with conventional radiography. Arthritis Rheum 2000; 43 : 2762-2770

[71] Hurnakova J, Filippucci E, Cipolletta E et al. Prevalence and distribution of cartilage damage at the metacarpal head level in rheumatoid arthritis and osteoarthritis: an ultrasound study. Rheumatology 2019; 58: 1206 1213

[72] Filer A, De Pablo P, Allen G et al. Utility of ultrasound joint counts in the prediction of rheumatoid arthritis in patients with very early synovitis. Ann Rheum Dis 2011; 70: 500-507

[73] Sahbudin I, Pickup L, Nightingale P et al. The role of ultrasound-defined tenosynovitis and synovitis in the prediction of rheumatoid arthritis development. Rheumatology 2018; 57: 1243-1252

[74] Naredo E, Rodríguez M, Campos C et al. Validity, reproducibility, and responsiveness of a twelve-joint simplified power doppler ultrasonographic assessment of joint inflammation in rheumatoid arthritis. Arthritis Rheum 2008; 59: 512-522

[75] Hammer HB, Kvien TK, Terslev L. Ultrasound of the hand is sufficient to detect subclinical inflammation in rheumatoid arthritis remission: a post hoc longitudinal study. Arthritis Res Ther 2017; 19: 221

[76] Freeston JE, Coates LC, Nam JL et al. Is there subclinical synovitis in early psoriatic arthritis? A clinical comparison with gray-scale and power Doppler ultrasound. Arthritis Care Res (Hoboken) 2014; 66: 432-439

[77] Ceccarelli F, Lucchetti R, Perricone $C$ et al. Musculoskeletal ultrasound in monitoring response to apremilast in psoriatic arthritis patients: results from a longitudinal study. Clin Rheumatol 2019; 38: 3145-3151

[78] Naranje P, Prakash M, Sharma A et al. Ultrasound findings in hand joints involvement in patients with psoriatic arthritis and its correlation with clinical DAS28 score. Radiol Res Pract 2015; 2015: 353657

[79] Salliot C, Denis A, Dernis E et al. Ultrasonography and detection of subclinical joints and tendons involvements in systemic lupus erythematosus [SLE] patients: A cross-sectional multicenter study. Joint Bone Spine 2018; 85: 741-745

[80] Han N, Tian X. Detection of subclinical synovial hypertrophy by musculoskeletal gray-scale/ power Doppler ultrasonography in systemic lupus erythematosus patients: A cross-sectional study. Int J Rheum Dis 2019; 22: 1058-1069

[81] Fujimura T, Fujimoto T, Hara R et al. Subclinical articular involvement in primary Sjögren's syndrome assessed by ultrasonography and its negative association with anti-centromere antibody. Mod Rheumatol 2015; 25: $871-875$

[82] Gunashekar S, Prakash M, Minz RW et al. Comparison of articular manifestations of mixed connective tissue disease and systemic lupus erythematosus on clinical examination and musculoskeletal ultrasound. Lupus 2018; 27: 2086-2092

[83] Ceccarelli F, Perricone C, Cipriano E et al. Usefulness of composite indices in the assessment of joint involvement in systemic lupus erythematosus patients: correlation with ultrasonographic score. Lupus 2019; 28 : $383-388$

[84] Guedes LKN, Leon EP, Bocate TS et al. Characterizing hand and wrist ultrasound pattern in primary Sjögren's syndrome: a case-control study. Clin Rheumatol 2020; 39: 1907-1918 
[85] Abdel-Magied RA, Lotfi A, AbdelGawad EA. Magnetic resonance imaging versus musculoskeletal ultrasonography in detecting inflammatory arthropathy in systemic sclerosis patients with hand arthralgia. Rheumatol Int 2013; 33: 1961-1966

[86] Lescoat A, Ballerie A, Belhomme $\mathrm{N}$ et al. Synovial involvement assessed by power Doppler ultra-sonography in systemic sclerosis: results of a cross-sectional study. Rheumatology (Oxford) 2018; 57: 2012-2021

[87] Kortekaas MC, Kwok WY, Reijnierse M et al. Brief Report: association of inflammation with development of erosions in patients with hand osteoarthritis: a prospective ultrasonography study. Arthritis Rheumatol 2016; 68: 392-397

[88] Mancarella L, Addimanda O, Pelotti P et al. Ultrasound detected inflammation is associated with the development of new bone erosions in hand osteoarthritis: a longitudinal study over 3.9 years. Osteoarthritis Cartilage 2015; 23: 1925-1932

[89] Mancarella L, Magnani M, Addimanda O et al. Ultrasound-detected synovitis with power Doppler signal is associated with severe radiographic damage and reduced cartilage thickness in hand osteoarthritis. Osteoarthritis Cartilage 2010; 18: 1263-1268

[90] Kortekaas MC, Kwok WY, Reijnierse M et al. Pain in hand osteoarthritis is associated with inflammation: the value of ultrasound. Ann Rheum Dis 2010; 69: 1367-1369

[91] Klauser AS, Faschingbauer R, Kupferthaler K et al. Sonographic criteria for therapy follow-up in the course of ultrasound-guided intra-articular injections of hyaluronic acid in hand osteoarthritis. Eur J Radiol 2012; 81: 1607-1611

[92] Roux C, Gandjbakhch F, Pierreisnard A et al. Ultrasonographic criteria for the diagnosis of erosive rheumatoid arthritis using osteoarthritic patients as controls compared to validated radiographic criteria. Joint Bone Spine 2019; 86: 467-474

[93] Vlychou M, Koutroumpas A, Malizos K et al. Ultrasonographic evidence of inflammation is frequent in hands of patients with erosive osteoarthritis. Osteoarthritis Cartilage 2009; 17: 1283-1287

[94] Martinoli C, Perez MM, Bignotti B et al. Imaging finger joint instability with ultrasound. Semin Musculoskelet Radiol 2013; 17: 466-476

[95] Klauser A, Bodner G, Frauscher F et al. Finger injuries in extreme rock climbers. Assessment of high-resolution ultrasonography. Am J Sports Med 1999; 27: 733-737

[96] Klauser A, Frauscher F, Bodner G et al. Value of high-resolution ultrasound in the evaluation of finger injuries in extreme sport climbers. Ultraschall in Med 2000; 21: 73-78

[97] Frediani B, Falsetti P, Storri L et al. Evidence for synovitis in active polymyalgia rheumatica: sonographic study in a large series of patients. J Rheumatol 2002; 29: 123-130

[98] Sakellariou G, lagnocco A, Meenagh G et al. Ultrasound imaging for the rheumatologist XXXVII. Sonographic assessment of the hip in ankylosing spondylitis patients. Clin Exp Rheumatol 2012; 30: 1-5

[99] Soini I, Kotaniemi A, Kautiainen $\mathrm{H}$ et al. US assessment of hip joint synovitis in rheumatic diseases. A comparison with MR imaging. Acta Radiol 2003; 44: 72-78

[100] Huwart A, Garrigues F, Jousse-Joulin S et al. Ultrasonography and magnetic resonance imaging changes in patients with polymyalgia rheumatica treated by tocilizumab. Arthritis Res Ther 2018; 20: 11

[101] Qvistgaard E, Torp-Pedersen S, Christensen R et al. Reproducibility and inter-reader agreement of a scoring system for ultrasound evaluation of hip osteoarthritis. Ann Rheum Dis 2006; 65: 1613-1619

[102] Jiménez-Palop M, Naredo E, Humbrado L et al. Ultrasonographic monitoring of response to therapy in polymyalgia rheumatica. Ann Rheum Dis 2010; 69: 879-882

[103] Bierma-Zeinstra SM, Oster JD, Bernsen RM et al. Joint space narrowing and relationship with symptoms and signs in adults consulting for hip pain in primary care. J Rheumatol 2002; 29: 1713-1718
[104] Di Matteo A, Filippucci E, Cipolletta E et al. Hip Involvement in Patients With Calcium Pyrophosphate Deposition Disease: Potenzial and Limits of Musculoskeletal Ultrasound. Arthritis Care Res (Hoboken) 2019; 71: 1671-1677

[105] Di Matteo A, Filippucci E, Cipolletta E et al. Ultrasound and clinical features of hip involvement in patients with gout. Joint Bone Spine 2019; 86: 633-636

[106] Hartung W, Kellner H, Strunk J et al. Development and evaluation of a novel ultrasound score for large joints in rheumatoid arthritis: one year of experience in daily clinical practice. Arthritis Care Res (Hoboken) 2012; 64: 675-882

[107] Schäfer VS, Fleck M, Kellner H et al. Evaluation of the novel ultrasound score for large joints in psoriatic arthritis and ankylosing spondylitis: six month experience in daily clinical practice. BMC Musculoskelet Disord 2013; 14: 358

[108] Wink F, Arends S, Maas F et al. High prevalence of hip involvement and decrease in inflammatory ultrasound lesions during tumour necrosis factor- $\alpha$ blocking therapy in ankylosing spondylitis. Rheumatology (Oxford) 2019; 58: 1040-1046

[109] Carsen S, Moroz PJ, Rakhra K et al. The Otto Aufranc Award. On the etiology of the cam deformity: a cross-sectional pediatric MRI study. Clin Orthop Relat Res 2014; 472: 430-436

[110] Palmer A, Fernquest S, Gimpel M et al. Physical activity during adolescence and the development of cam morphology: a cross-sectional cohort study of 210 individuals. Br J Sports Med 2018; 52: 601-610

[111] van Klij P, Heijboer MP, Ginai AZ et al. Cam morphology in young male football players mostly develops before proximal femoral growth plate closure: a prospective study with 5-yearfollow-up. Br J Sports Med 2019; 53: 532-538

[112] Buck FM, Hodler ], Zanetti M et al. Ultrasound for the evaluation of femorocetabular impingement of the cam type. Diagnostic performance of qualitative criteria and alpha angle measurements. Eur Radiol 2011; 21: $167-175$

[113] Lerch S, Kasperczyk A, Warnecke J et al. Evaluation of cam-type femoroacetabular impingement by ultrasound. Int Orthop 2013; 37: 783788

[114] Lerch S, Kasperczyk A, Berndt T et al. Ultrasound is as reliable as plain radiographs in the diagnosis of cam-type femoroacetabular impingement. Arch Orthop Trauma Surg 2016; 136: 1437-1443

[115] Orellana C, Moreno M, Calvet J et al. Ultrasound findings in patients with femoracetabular impingement without radiographic osteoarthritis: A Pilot Study. J Ultrasound Med 2019; 38: 895-901

[116] Mandema L, Tak I, Mooij B et al. Assessment of cam morphology of the hip with ultrasound imaging by physical therapists is reliable and valid. Phys Ther Sport 2018; 32: 167-172

[117] Jin W, Kim KI, Rhyu KH et al. Sonographic evaluation of anterosuperior hip labral tears with magnetic resonance, arthrographic and surgical correlation. J Ultrasound Med 2012; 31: 439-447

[118] Gao G, Fu Q, Cui L et al. The diagnostic value of ultrasound in anterosuperior acetabular labral tear. Arthroscopy 2019; 35: 2591-2597

[119] Jung JY, Kim GU, Lee HJ et al. Diagnostic Value of Ultrasound and Computed Tomographic Arthrography in Diagnosing Anterosuperior Acetabular Labral Tears. Arthroscopy 2013; 29: 1769-1776

[120] Troelsen A, Mechlenburg I, Gelineck J et al. What is the role of clinical tests and ultrasound in acetabular labral tear diagnostics? Acta Orthop 2009; 80: 314-318

[121] Bialecki J, Bartosz P, Marczynski W et al. Usefulness of ultrasonography in the diagnosis of hematoma after primary hip arthroplasty. J Ultrason 2017; 17: 149-153

[122] Hoefnagels EM, Bradov M, Reijnierse M et al. Sonography after total hip replacement - Reproducibility and normal values in 47 clinically uncomplicated cases. Acta Orthop 2007; 78: 81-85 
[123] Tarasevicius S, Skikas L, Mitraite D et al. Sonography in total hip arthroplasty. Ultraschall in Med 2007; 28: 475-478

[124] Guillin R, Bertaud V, Garetier M et al. Ultrasound in Total Hip Replacement: Value of Anterior Acetabular Cup Visibility and Contact With the Iliopsoas Tendon. J Ultrasound Med 2018; 37: 1439-1446

[125] Siddiqui IA, Sabah SA, Satchithananda K et al. A comparison of the diagnostic accuracy of MARS MRI and ultrasound of the painful metalon-metal hip arthroplasty. Acta Orthop 2014; 85: 375-382

[126] Garbuz DS, Hargreaves BA, Duncan CP et al. The John Charnley Award: Diagnostic Accuracy of MRI Versus Ultrasound for Detecting Pseudotumors in Asymptomatic Metal-on-Metal THA. Clin Orthop Relat Res 2014; 472: 417-423

[127] Muraoka K, Naito M, Nakamura Y et al. Usefulness of Ultrasonography for Detection of Pseudotumors After Metal-On-Metal Total Hip Arthroplasty. J Arthroplasty 2015; 30: 879-884

[128] Kwon YM, Dimitriou D, Liow MHL et al. Is Ultrasound As Useful As Metal Artifact Reduction Sequence Magnetic Resonance Imaging in Longitudinal Surveillance of Metal-on-Metal Hip Arthroplasty Patients? J Arthroplasty 2016; 31: 1821-1827

[129] Yucesoy C, Genc G, Bal A et al. Ultrasonographic Assessment of Knee in Patients with Rheumatoid Arthritis: Is it an Effective Imaging Method for Initial Evaluation? Turk J Rheumatol 2011; 26: 120-126

[130] Najm A, Orr C, Gallagher L et al. Knee joint synovitis: study of correlations and diagnostic performances of ultrasonography compared with histopathology. RMD Open 2018; 4: e000616

[131] Lee KA, Lee SH, Kim HR. Diagnostic value of ultrasound in calcium pyrophosphate deposition disease of the knee joint. Osteoarthritis Cartilage 2019; 27: 781-787

[132] Ruta S, Catay E, Marin J et al. Knee effusion: ultrasound as a useful tool for the detection of calcium pyrophosphate crystals. Clin Rheumatol 2016; 35: 1087-1091

[133] Filippou G, Scirè CA, Damjanov N et al. Definition and reliability assessment of elementary ultrasonographic findings in calcium pyrophosphate deposition disease: a study by the OMERACT calcium pyrophosphate deposition disease ultrasound subtask force. J Rheumatol 2017; 44: 1744-1749

[134] Kane D, Balint PV, Sturrock RD. Ultrasonography is superior to clinical examination in the detection and localization of knee joint effusion in rheumatoid arthritis. J Rheumatol 2003; 30: 966-971

[135] Ossandon A, lagnocco A, Alessandri C et al. Ultrasonographic depiction of knee joint alterations in systemic lupus erythematosus. Clin Exp Rheumatol 2009; 27: 329-332

[136] Filippucci E, Scirè CA, Delle Sedie A et al. Ultrasound Imaging for the Rheumatologist. XXV. Sonographic Assessment of the Knee in Patients With Gout and Calcium Pyrophosphate Deposition Disease. Clin Exp Rheumatol 2010; 28: 2-5

[137] Strobl S, Halpern EJ, Abd Ellah M et al. Acute Gouty Knee Arthritis: Ultrasound Findings Compared With Dual-Energy CT Findings. Am J Roentgenol 2018; 210: 1323-1329

[138] Gutierrez M, Schmidt WA, Thiele RG et al. International Consensus for Ultrasound Lesions in Gout. Results of Delphi Process and Web-Reliability Exercise. Rheumatology 2015; 54: 1797-1805

[139] Terslev L, Gutierrez M, Schmidt WA et al. OMERACT Ultrasound Working Group. Ultrasound as an Outcome Measure in Gout. A Validation Process by the OMERACT Ultrasound Working Group. J Rheumatol 2015; 42: 2177-2181

[140] Barskova VG, Kudaeva FM, Bozhieva LA et al. Comparison of three imaging techniques in diagnosis of chondrocalcinosis of the knees in calcium pyrophosphate deposition disease. Rheumatology 2013; 52: 1090-1094

[141] Ottaviani S, Juge PA, Aubrun A et al. Sensitivity and Reproducibility of Ultrasonography in Calcium Pyrophosphate Crystal Deposition in Knee Cartilage: A Cross-sectional Study. J Rheumatol 2015; 42: 1511-1513
[142] Serban O, Porojan M, Deac M et al. Pain in bilateral knee osteoarthritis - correlations between clinical examination, radiological, and ultrasonographical findings. Med Ultrason 2016; 18: 318-325

[143] Sarmanova A, Hall M, Fernandes GS et al. Association between ultrasound-detected synovitis and knee pain: a population-based case-control study with both cross-sectional and follow-up data. Arthritis Res Ther 2017; 19: 281

[144] Bruyn GA, Naredo E, Damjanov N et al. An OMERACT reliability exercise of inflammatory and structural abnormalities in patients with knee osteoarthritis using ultrasound assessment. Ann Rheum Dis 2016; 75: 842-846

[145] Hirsch G, O’Neill T, Kitas G et al. Distribution of effusion in knee arthritis as measured by high-resolution ultrasound. Clin Rheumatol 2012; 31: 1243-1246

[146] Conaghan PG, D’Agostino MA, Le Bars M et al. Clinical and ultrasonographic predictors of joint replacement for knee osteoarthritis: results from a large, 3-year, prospective EULAR study. Ann Rheum Dis 2010; 69: 644-647

[147] Chiba D, Sasaki E, Ota S et al. US detection of medial meniscus extrusion can predict the risk of developing radiographic knee osteoarthritis: a 5-year cohort study. Eur Radiol 2020; 30: 3996-4004

[148] Nogueira-Barbosa MH, Gregio-Junior E, Lorenzato MM et al. Ultrasound Assessment of Medial Meniscal Extrusion: A Validation Study Using MR as Reference Standard. AR Am J Roentgenol 2015; 204: 584-588

[149] Acebes C, Romero FI, Contreras MA et al. Dynamic ultrasound assessment of medial meniscal subluxation in knee osteoarthritis. Rheumatology 2013; 52: 1443-1447

[150] Koski JM, Kamel A, Waris P et al. Atlas-based knee osteophyte assessment with ultrasonography and radiography: relationship to arthroscopic degeneration of articular cartilage. Scand J Rheumatol 2016; 45 $158-164$

[151] Mortada M, Zeid A, Al-Toukhy MA et al. Reliability of a Proposed Ultrasonographic Grading Scale for Severity of Primary Knee Osteoarthritis. Clin Med Insights Arthritis Musculoskelet Disord 2016; 9: 161-166

[152] Cao J, Zheng B, Meng X et al. A novel ultrasound scanning approach for evaluating femoral cartilage defects of the knee: comparison with routine magnetic resonance imaging. J Orthop Surg Res 2018; 13: 178

[153] Pradsgaard DO, Fiirgaard B, Spannow AH et al. Cartilage Thickness of the Knee Joint in Juvenile Idiopathic Arthritis: Comparative Assessment by Ultrasonography and Magnetic Resonance Imaging. J Rheumatol 2015; 42: 534-540

[154] Maeguchi K, Ito H, Morita Y et al. How precisely does ultrasonographic evaluation reflect the histological status of the articular cartilage of the knee joint? J Orthop 2018; 15: 636-640

[155] Özçakar L, Tunc H, Oken O et al. Femoral cartilage thickness measurements in healthy individuals: Learning, practicing and publishing with TURK-MUSCULUS. J Back Musculoskelet Rehabil 2014; 27: 117-124

[156] Schmidt GL, Lippmann S, Unverzagt S et al. Diagnostik bei Frakturverdacht - Ultraschall im Vergleich zu konventioneller Bildgebung. Dtsch Arztebl 2017; 114: 757-764

[157] Friedman L, Finlay K, Juriaans E. Ultrasound of the knee. Skeletal Radio 2002; 30: 361-377

[158] Akatsu Y, Yamaguchi S, Mukoyama S et al. Accuracy of high-resolution ultrasound in the detection of meniscal tears and determination of the visible area of menisci. J Bone Joint Surg Am 2015; 97: 799-806

[159] Dai H, Huang ZG, Chen Z] et al. Diagnostic accuracy of ultrasonography in assessing meniscal injury: meta-analysis of prospective studies. J Orthop Sci 2015; 20: 675-681

[160] Cook JL, Cook CR, Stannard JP et al. MRI versus ultrasonography to assess meniscal abnormalities in acute knees. J Knee Surg 2014; 27: 319 324 
[161] Wareluk P, Szopinski KT. Value of modern sonography in the assessment of meniscal lesions. Eur J Radiol 2012; 81: 2366-2369

[162] Cavaignac E, Faruch M, Wytrykowski K et al. Ultrasonographic Evaluation of Anterolateral Ligament Injuries: Correlation With Magnetic Resonance Imaging and Pivot-Shift Testing. Arthroscopy 2017; 33: 1384-1390

[163] Zhang GY, Zheng L, Shi H et al. Sonography on injury of the medial patellofemoral ligament after acute traumatic lateral patellar dislocation: Injury patterns and correlation analysis with injury of articular cartilage of the inferomedial patella. Injury 2013; 44: 1892-1898

[164] Yoshida M, Herbst E, Albers M et al. The anterolateral complex in anterior cruciate ligament deficient knees demonstrate sonographic abnormalities on high-resolution sonography. Knee Surg Sports Traumatol Arthrosc 2017: 25: 1024-1029

[165] Zhang GY, Zheng L, Ding HY et al. Evaluation of medial patellofemoral ligament tears after acute lateral patellar dislocation: comparison of high-frequency ultrasound and MR. Eur Radiol 2015; 25: 274-281

[166] Cho KH, Lee DC, Chhem RK et al. Normal and acutely torn posterior cruciate ligament of the knee at US evaluation: preliminary experience. Radiology 2001; 219: 375-380

[167] Sievert ZA, Bennett H], Weinhand JT. Intra- and inter-rater reliability of ultrasound measures of the anterior cruciate ligament. J Ultrasound 2020. doi:10.1007/s40477-020-00450-1

[168] Bergenthal G, Schwarz W, Gerngross H et al. Functional ultrasound examination of the posterior cruciate ligament - a new method of detecting ligament instability in the knee joint. Ultraschall in Med 2005; 26: $120-126$

[169] Palm HG, Bergenthal G, Ehry P et al. Functional ultrasonography in the diagnosis of acute anterior cruciate ligament injuries: a field study. Knee 2009; 16: 441-446

[170] Wang J, Wu H, Dong F et al. The role of ultrasonography in the diagnosis of anterior cruciate ligament injury: A systematic review and metaanalysis. Eur J Sport Sci 2018; 18: 579-586

[171] Möller I, Janta I, Backhaus M et al. The 2017 EULAR standardised procedures for ultrasound imaging in rheumatology. Ann Rheum Dis 2017; 76: 1974-1979

[172] Bruyn GAW, Siddle H], Hanova P et al. Ultrasound of Subtalar Joint Synovitis in Patients with Rheumatoid Arthritis: Results of an OMERACT Reliability Exercise Using Consensual Definitions. J Rheumatol 2019; 46: 351-359

[173] Kitchen J, Kane D. Greyscale and power Doppler ultrasonographic evaluation of normal synovial joints: correlation with pro- and anti-inflammatory cytokines and angiogenic factors. Rheumatology (Oxford) 2015; 54: 458-462

[174] Micu MC, Fodor D, Micu R et al. Pregnant versus non-pregnant healthy subjects - a prospective longitudinal musculoskeletal ultrasound study concerning the spectrum of normality. Med Ultrason 2018; 20: 319327

[175] Șerban O, Bădărînză M, Fodor D. The relevance of ultrasound examination of the foot and ankle in patients with rheumatoid arthritis a review of the literature. Med Ultrason 2019; 21: 175-182

[176] Inamo J, Kaneko Y, Sakata K et al. Impact of subclinical synovitis in ankles and feet detected by ultrasonography in patients with rheumatoid arthritis. Int J Rheum Dis 2019; 22: 62-67

[177] Wakefield RJ, Karim Z, Conaghan PG. Sonography is more sensitive at detecting synovitis in the metatarsophalangeal joints than clinical examination. Ann Rheum Dis 1999; 42: s 352

[178] Riente L, Delle Sedie A, Scirè CA et al. Ultrasound imaging for the rheumatologist. XXXI. Sonographic assessment of the foot in patients with rheumatoid arthritis. Clin Exp Rheumatol 2011; 29: 1-5

[179] Ciurtin C, Jones A, Brown G et al. Real benefits of ultrasound evaluation of hand and foot synovitis for better characterisation of the disease activity in rheumatoid arthritis. Eur Radiol 2019; 29: 6345-6354
[180] Hernandez-Diaz C, Sanchez-Bringas G, Ventura-Rios L et al. Ankle pain in rheumatoid arthritis: comparison of clinical and sonographic findings. Clin Rheumatol 2019; 38: 2891-2895

[181] Șerban O, Papp I, Bocșa CD et al. Do ankle, hindfoot, and heel ultrasound findings predict the symptomatology and quality of life in rheumatoid arthritis patients? J Ultrason 2020; 20: e70-e82

[182] Alsuwaidi M, Ehrenstein B, Fleck M et al. Asymptomatic Versus Symptomatic Ankle Joints in Rheumatoid Arthritis: A High-Resolution BMode and Power Doppler Ultrasound Study. Arthritis Care Res 2016; 68: $861-864$

[183] Enache L, Popescu CC, Micu MC et al. Ankle involvement in rheumatoid arthritis - a comparison of inflammatory signs on musculoskeletal ultrasound and magnetic resonance imaging. Med Ultrason 2019; 21: 265-272

[184] Sant'Ana Petterle G, Natour ], Rodrigues da Luz K et al. Usefulness of US to show subclinical joint abnormalities in asymptomatic feet of RA patients compared to healthy controls. Clin Exp Rheumatol 2013; 31: 904-912

[185] Serban O, Fodor D, Papp I et al. Reasons for discordances between ultrasonography and magnetic resonance imaging in the evaluation of the ankle, hindfoot and heel of the patients with rheumatoid arthritis. Med Ultrason 2019; 21: 405-413

[186] Janta I, Valor L, De la Torre I et al. Ultrasound-detected activity in rheu matoid arthritis on methotrexate therapy: Which joints and tendons should be assessed to predict unstable remission? Rheumatol Int 2016; 36: 387-396

[187] Wechalekar MD, Lester S, Hill CL et al. Active foot synovitis in patients with rheumatoid arthritis: unstable remission status, radiographic progression, and worse functional outcomes in patients with foot synovitis in apparent remission. Arthritis Care Res (Hoboken) 2016; 68: 16161623

[188] Onodera T, Kasahara Y, Kasemura T et al. A Comparative Study With In Vitro Ultrasonographic and Histologic Grading of Metatarsal Head Cartilage in Rheumatoid Arthritis. Foot Ankle Int 2015; 36: 774-779

[189] Lopez-Ben R, Bernreuter WK, Moreland LW et al. Ultrasound detection of bone erosions in rheumatoid arthritis: a comparison to routine radiographs of the hands and feet. Skeletal Radiol 2004; 33: 80-84

[190] Szkudlarek M, Narvestad E, Klarlund M et al. Ultrasonography of the metatarsophalangeal joints in rheumatoid arthritis: comparison with magnetic resonance imaging, conventional radiography, and clinical examination. Arthritis Rheum 2004; 50: 2103-2112

[191] Wakefield RJ, Freeston JE, O'Connor P et al. The optimal assessment of the rheumatoid arthritis hind foot: a comparative study of clinical examination, ultrasound and high field MRI. Ann Rheum Dis 2008; 67: 1678-1672

[192] Schmidt WA, Schicke B, Ostendorf B et al. Low-field MRI versus ultrasound: which is more sensitive in detecting inflammation and bone damage in MCP and MTP joints in mild or moderate rheumatoid arthritis? Clin Exp Rheumatol 2013; 31: 91-96

[193] Szudlarek M, Court-Payen M, Jacobsen S et al. Interobserver agreement in ultrassonography of the finger and toe joints in rheumatoid arthritis. Arthritis Rheum 2003; 48: 955-962

[194] Delle Sedie A, Riente L, Fillipucci E et al. Ultrasound imaging for the rheumatologist. XXXII. Sonographic assessment of the foot in patients with psoriatic arthritis. Clin Exp Rheumatol 2011; 29: 217-222

[195] Turner DE, Hyslop E, Barn R et al. Metatarsophalangeal joint pain in psoriatic arthritis: a cross-sectional study. Rheumatology 2014; 53 : 737-740

[196] Wiell C, Szkudlarek M, Hasselquist M et al. Ultrasonography, magnetic resonance imaging, radiography, and clinical assessment of inflammatory and destructive changes in fingers and toes of patients with psoriatic arthritis. Arthritis Res Ther 2007; 9: R119 
[197] Weiner SM, Jurenz S, Uhl M et al. Ultrasonography in the assessment of peripheral joint involvement in psoriatic arthritis - A comparison with radiography, MRI and scintigraphy. Clin Rheumatol 2008; 27: 983-989

[198] Gutierrez M, Di Geso L, Salaffi F et al. Development of a preliminary US power Doppler composite score for monitoring treatment in PsA. Rheumatology 2012; 51: 1261-1268

[199] Ficjan A, Husic R, Gretler ] et al. Ultrasound composite scores for the assessment of inflammatory and structural pathologies in psoriatic arthritis (PsASon-Score). Arthritis Res Ther 2014; 16: 476

[200] El Miedany Y, El Gaafary M, Youssef S et al. Tailored approach to early psoriatic arthritis patients: clinical and ultrasonographic predictors for structural joint damage. Clin Rheumatol 2015; 34: 307-313

[201] Ruta S, Martin J, Acosta Felquer ML et al. Utility of Power Doppler Ultrasound-detected synovitis for the prediction of short-term flare in psoriatic patients with arthritis in clinical remission. J Rheumatol 2017; 44: 1018-1023

[202] Kang MH, Moon KW, Jeon YH et al. Sonography of the First Metatarsophalangeal Joint and Sonographically Guided Intraarticular Injection of Corticosteroid in Acute Gout Attack. J Clin Ultrasound 2015; 43: 179186

[203] Roddy E, Menon A, Hall A et al. Polyarticular sonographic assessment of gout: A hospital-based cross-sectional study. Joint Bone Spine 2013; 80: 295-300

[204] Stewart S, Dalbeth N, Vandal AC et al. Are ultrasound features at the first metatarsophalangeal joint associated with clinically-assessed pain and function? A study of people with gout, asymptomatic hyperuricaemia and normouricaemia. J Foot Ankle Res 2017; 10: 22

[205] Wright SA, Filippucci E, McVeigh C et al. High-resolution ultrasonography of the first metatarsal phalangeal joint in gout: a controlled study. Ann Rheum Dis 2007; 66: 859-864

[206] Zhang W, Jin Z, Xiang W et al. Ultrasonographic Features of Lower-Limb Joints in Gout Which Joints and Clinical Characteristics Would Provide More Information for Diagnosis? J Clin Rheumatol 2020; 26: 14-18

[207] Terslev L, Gutierrez M, Christensen R et al. Assessing Elementary Lesions in Gout by Ultrasound: Results of an OMERACT Patient-based Agreement and Reliability Exercise. J Rheumatol 2015; 42: 2149-2154

[208] Naredo E, Uson J, Jiménez-Palop M et al. Ultrasound-detected musculoskeletal urate crystal deposition: which joints and what findings should be assessed for diagnosing gout? Ann Rheum Dis 2014; 73 : 1522-1528

[209] lagnocco A, Ceccarelli F, Rizzo C et al. Ultrasound evaluation of hand, wrist and foot joint synovitis in systemic lupus erythematosus. Rheumatology 2014; 53: 465-472

[210] Morales-Lozano R, Martínez-Barrio ], González-Fernández ML et al. The feet in systemic lupus erythematosus; are we underestimating their involvement and functional impact? Clin Exp Rheumatol 2016; 34 : 609-617

[211] Mukherjee S, Cherry L, Zarroug J et al. A pilot investigation of the prevalence of US-detectable forefoot joint pathology and reported foot-related disability in participants with systemic lupus erythematosus. J Foot Ankle Res 2016; 9: 27

[212] Le Bras E, Ehrenstein B, Fleck M et al. Evaluation of Ankle Swelling Due to Lofgren's Syndrome: A Pilot Study Using B-Mode and Power Doppler Ultrasonography. Arthritis Care Res 2014; 66: 318-322

[213] Goussault C, Albert JD, Coiffier G et al. Ultrasound characterization of ankle involvement in Löfgren syndrome. Joint Bone Spine 2018; 85: 65-69

[214] Zabotti A, Filippou G, Canzoni M et al. OMERACT agreement and reliability study of ultrasonographic elementary lesions in osteoarthritis of the foot. RMD Open 2019; 5: e000795

[215] lagnocco A, Filippucci E, Riente L et al. Ultrasound imaging for the rheumatologist XXXV. Sonographic assessment of the foot in patients with osteoarthritis. Clin Exp Rheumatol 2011; 29: 757-762
[216] Keen HI, Redmond A, Wakefield R] et al. An ultrasonographic study of metatarsophalangeal joint pain: synovitis, structural pathology and their relationship to symptoms and function. Ann Rheum Dis 2011; 70 2140-2143

[217] Proft F, Grunke M, Reindl C et al. The influence of long distance running on sonographic joint and tendon pathology: results from a prospective study with marathon runners. BMC Musculoskelet Disord 2016; 17: 272

[218] Guillodo Y, Riban P, Guennoc X et al. Usefulness of ultrasonographic detection of talocrural effusion in ankle sprains. J Ultrasound Med 2007; 26: 831-836

[219] Roth J, Jousse-Joulin S, Magni-Manzoni S et al. Definitions for the sonographic features of joints in healthy children. Arthritis Care Res 2015; 67: $136-142$

[220] Collado P, Windschall D, Vojinovic ] et al. Amendment of the OMERACT ultrasound definitions of joints' features in healthy children when using the DOPPLER technique. Pediatr Rheumatol Online J 2018; 16: 23

[221] Esposito F, Ferrara D, Di Serafino M et al. Classification and ultrasound findings of vascular anomalies in pediatric age: the essential. J Ultrasound 2019; 22: 13-25

[222] Graf R. Hip sonography: background; technique and common mistakes; results; debate and politics; challenges. Hip Int 2017; 27: 215219

[223] Colebatch-Bourn AN, Edwards C], Collado P et al. EULAR-PReS points to consider for the use of imaging in the diagnosis and management of juvenile idiopathic arthritis in clinical practice. Ann Rheum Dis 2015; 74: 1946-1957

[224] Rotter A, Samorano LP, de Oliveira Labinas GH et al. Ultrasonography as an objective tool for assessment of infantile hemangioma treatment with propranolol. Int J Dermatol 2017; 56: 190-194

[225] Laurell L, Court-Payen M, Nielsen S et al. Ultrasonography and color Doppler in juvenile idiopathic arthritis: diagnosis and follow-up of ultrasound-guided steroid injection in the ankle region. A descriptive interventional study. Pediatr Rheumatol Online J 2011; 9: 4

[226] Eltomey MA, Madej T. Lower Limb: Hip and Thigh. In: El Miedany Y, editor. Pediatric Musculoskeletal Sonography. Switzerland: Springer; 2019: 131-177

[227] Chauvin NA, Ho-Fung V, Jaramillo D et al. Ultrasound of the joints and entheses in healthy children. Pediatr Radiol 2015; 45: 1344-1354

[228] Collado P, Naredo E, Calvo C et al. Assessment of the joint recesses and tendon sheaths in healthy children by high-resolution B-mode and power Doppler sonography. Clin Exp Rheumatol 2007; 25: 915-921

[229] Rosendahl K, Bruserud IS, Oehme N et al. Normative ultrasound references for the paediatric wrist; dorsal soft tissues. RMD Open 2018; 4 : e000642

[230] Windschall D, Trauzeddel R, Haller M et al. Pediatric musculoskeletal ultrasound: age- and sex-related normal B-mode findings of the knee. Rheumatol Int 2016; 36: 1569-1577

[231] Jousse-Joulin S, Cangemi C, Alavi Z et al. Normal sonoanatomy of small joints in healthy children: changes in cartilage and vascularisation according to age and gender. Clin Exp Rheumatol 2018; 36: 1103-1109

[232] Spannow AH, Pfeiffer-Jensen M, Andersen NT et al. Ultrasonographic Measurements of Joint Cartilage Thickness in Healthy Children: Ageand Sex-Related Standard Reference Values. J Rheumatol 2010; 37: 2595-2601

[233] Samanta M, Mitra S, Samui PP et al. Evaluation of joint cartilage thickness in healthy children by ultrasound: An experience from a developing nation. Int J Rheum Dis 2018; 21: 2089-2094

[234] Trauzeddel RF, Lehmann H, Windschall D et al. Age-dependent arthrosonographic reference values of the hip joint in healthy children and adolescents - a cross-sectional multicenter ultrasound study. Pediatr Radiol 2017; 47: 1329-1336 
[235] Trauzeddel R, Windschall D, Trauzeddel RF et al. Arthrosonographic reference values of the shoulder joint in healthy children and adolescents: a cross-sectional multicentre ultrasound study. Klin Padiatr 2017; 229: 293-301

[236] Roth J, Stinson SE, Chan J et al. Differential pattern of Doppler signals at lower-extremity entheses of healthy children. Pediatr Radiol 2019; 49: 1335-1343

[237] Jousse-Joulin S, Cangemi C, Gerard S et al. Normal sonoanatomy of the paediatric entheses including echostructure and vascularisation changes during growth. Eur Radiol 2015; 25: 2143-2152

[238] Filippou G, Cantarini L, Bertoldi I et al. Ultrasonography vs. clinical examination in children with suspected arthritis. Does it make sense to use poliarticular ultrasonographic screening? Clin Exp Rheumatol 2011; 29: 345-350

[239] Janow GL, Panghaal V, Trinh A et al. Detection of active disease in juvenile idiopathic arthritis: sensitivity and specificity of the physical examination vs ultrasound. J Rheumatol 2011; 38: 2671-2674

[240] Kakati P, Sodhi KS, Sandhu MS et al. Clinical and ultrasound assessment of the knee in children with juvenile rheumatoid arthritis. Indian J Pediatr 2007; 74: 831-836

[241] El-Banna HS, Nada DW, Hussein MS et al. Role of musculoskeletal ultrasonography in the detection of subclinical synovitis in oligo and polyarticular juvenile idiopathic arthritis children. Egypt Rheumatol 2019; 41: 151-155

[242] Haslam KE, McCann L], Wyatt S et al. The detection of subclinical synovitis by ultrasound in oligoarticular juvenile idiopathic arthritis: a pilot study. Rheumatology 2010; 49: 123-127

[243] Hassan H, El Ganzouri AMI, Ahmed SF et al. High frequency power doppler ultrasonography in oligoarticular juvenile idiopathic arthritis: Correlation with disease severity. Egypt Rheumatol 2015; 37: 125-131

[244] Lanni S, Marafon DP, Civino A et al. Comparison between clinical and ultrasound assessment of the ankle region in juvenile idiopathic arthritis. Arthritis Care Res (Hoboken) 2020. doi:10.1002/acr.24241

[245] Magni-Manzoni S, Epis O, Ravelli A et al. Comparison of clinical versus ultrasound-determined synovitis in juvenile idiopathic arthritis. Arthritis Rheum 2009; 61: 1497-1504

[246] Breton S, Jousse-Joulin S, Cangemi C et al. Comparison of clinical and ultrasonographic evaluations for peripheral synovitis in juvenile idiopathic arthritis. Semin Arthritis Rheum 2011; 41: 272-278

[247] Lanni S, van Dijkhuizen EHP, Vanoni F et al. Ultrasound changes in synovial abnormalities induced by treatment in juvenile idiopathic arthritis. Clin Exp Rheumatol 2018; 36: 329-334

[248] Collado P, Vojinovic ], Nieto JC et al. Toward standardized musculoskeletal ultrasound in pediatric rheumatology: normal age-related ultrasound findings. Arthritis Care Res 2016; 68: 348-356

[249] Collado P, Naredo E, Calvo C et al. Reduced joint assessment vs comprehensive assessment for ultrasound detection of synovitis in juvenile idiopathic arthritis. Rheumatology 2013; 52: 1477-1484

[250] Weiss PF, Arabshahi B, Johnson A et al. High prevalence of TM] involvement in 32 new-onset JIA patients, as detected by magnetic resonance imaging but not by ultrasound. Arthritis Rheum 2008; 58: 1189-1196

[251] Muller L, Kellenberger C], Cannizzaro E et al. Early diagnosis of temporomandib- ular joint involvement in juvenile idiopathic arthritis: a pilot study comparing clinical examination and ultrasound to magnetic resonance imaging. Rheumatology 2009; 48: 680-685

[252] Magni-Manzoni S, Scirè CA, Ravelli A et al. Ultrasound-detected synovial abnormalities are frequent in clinically inactive juvenile idiopathic arthritis, but do not predict a flare of synovitis. Ann Rheum Dis 2013; 72: $223-228$

[253] De Lucia O, Ravagnani V, Pregnolato F et al. Baseline ultrasound examination as possible predictor of relapse in patients affected by juvenile idiopathic arthritis. Ann Rheuma Dis 2018; 77: 1426-1431
[254] Miotto E Silva VB, Mitraud SAV, Furtado RNV et al. Patients with juvenile idiopathic arthritis in clinical remission with positive power Doppler signal in joint ultrasonography have an increased rate of clinical flare: a prospective study. Pediatr Rheumatol Online 2017; 15: 80

[255] Rebollo-Polo M, Koujok K, Weisser C et al. Ultrasound findings on patients with juvenile idiopathic arthritis in clinical remission. Arthritis Care Res (Hoboken) 2011; 63: 1013-1019

[256] Nieto-González JC, Rodríguez A, Gámir-Gámir ML et al. Can ultrasound detected subclinical synovitis be an indicator of flare recurrence in juvenile idiopathic arthritis remission patients on tapered TNFi? Clin Exp Rheumatol 2019; 37: 705-712

[257] Zhao Y, Rascoff NE, lyer RS et al. Flares of disease in children with clinically inactive juvenile idiopathic arthritis were not correlated with ultrasound findings. J Rheumatol 2018; 45: 851-857

[258] Malattia C, Damasio MB, Magnaguagno F et al. Magnetic Resonance Imaging, Ultrasonography, and Conventional Radiography in the assessment of bone erosions in juvenile idiopathic arthritis. Arthritis Rheum 2008; 59: 1764-1772

[259] Karmazyn B, Bowyer SL, Schmidt KM et al. US findings of metacarpophalangeal joints in children with idiopathic juvenile arthritis. Pediatr Radiol 2007; 37: 475-482

[260] El-Miedany YM, Housny IH, Mansour HM et al. Ultrasound versus MRI in the evaluation of juvenile idiopathic arthritis of the knee. Joint Bone Spine 2001; 68: 222-230

[261] Laine JC, Denning JR, Riccio Al et al. The use of ultrasound in the management of septic arthritis of the hip. J Pediatr Orthop B 2015; 24: 9598

[262] Bono KT, Samora JB, Klingele KE. Septic arthritis in infants younger than 3 months: a retrospective review. Orthopedics 2015; 38: e787-e793

[263] Chin TWY, Tse KS. Clinical and Radiological Differentiation of Septic Arthritis and Transient Synovitis of the Hip. Hong Kong J Radiol 2017; 20: 41-46

[264] Bessar MA, Hassan HA, Mokhtar WA. Role of high resolution ultrasonography in diagnosing septic hip arthritis in premature neonates admitted to the neonatal intensive care unit. Egypt J Radiol Nucl Med 2017; 48: 971-975

[265] Zamzam MM. The role of ultrasound in differentiating septic arthritis from transient synovitis of the hip in children. J Pediatr Orthop B 2006; 15: $418-422$

[266] Kaneuchi Y, Otoshi K, Hakozaki M et al. Bony Maturity of the Tibial Tuberosity With Regard to Age and Sex and Its Relationship to Pathogenesis of Osgood-Schlatter Disease An Ultrasonographic Study. Orthop J Sports Med 2018; 6: 2325967117749184

[267] Sailly M, Whiteley R, Johnson A. Doppler ultrasound and tibial tuberosity maturation status predicts pain in adolescent male athletes with Osgood-Schlatter's disease: a case series with comparison group and clinical interpretation. Br J Sports Med 2013; 47: 93-97

[268] Ducher G, Cook ], Lammers G et al. The ultrasound appearance of the patellar tendon attachment to the tibia in young athletes is conditional on gender and pubertal stage. J Sci Med Sport 2010; 13: 20-23

[269] Toprak U, Ustuner E, Uyanik S et al. Comparison of ultrasonographic patellar tendon evaluation methods in elite junior female volleyball players: thickness versus cross-sectional area. Diagn Interv Radiol 2012; 18: 200-207

[270] Akinmade A, Ikem I, Ayoola O et al. Comparing ultrasonography with plain radiography in the diagnosis of paediatric long-bone fractures. Int Orthop 2019; 43: 1143-1153

[271] Barata I, Spencer R, Suppiah A et al. Emergency Ultrasound in the Detection of Pediatric Long-Bone Fractures. Pediatr Emerg Care 2012; 28: 1154-1157

[272] Beltrame V, Stramare R, Rebellato $\mathrm{N}$ et al. Sonographic evaluation of bone fractures: a reliable alternative in clinical practice? Clin Imaging 2012; 36: 203-208 
[273] Lee SH, Yun S]. Diagnostic Performance of Ultrasonography for Detection of Pediatric Elbow Fracture: A Meta-analysis. Ann Emerg Med 2019; 74: 493-502

[274] Eckert K, Janssen N, Ackermann O et al. Ultrasound diagnosis of supracondylar fractures in children. Eur J Trauma Emerg Surg 2014; 40: 159168

[275] Burnier M, Buisson G, Ricard A et al. Diagnostic value of ultrasonography in elbow trauma in children: Prospective study of 34 cases. Orthop Traumatol Surg Res 2016; 102: 839-843

[276] Eckert K, Ackermann O, Janssen $\mathrm{N}$ et al. Accuracy of the sonographic fat pad sign for primary screening of pediatric elbow fractures: a preliminary study. J Med Ultrason 2014; 41: 473-480

[277] Neri E, Barbi E, Rabach I et al. Diagnostic accuracy of ultrasonography for hand bony fractures in paediatric patients. Arch Dis Child 2014; 99 : 1087-1090

[278] Aksay E, Yesilaras M, Kilic TY et al. Sensitivity and specificity of bedside ultrasonography in the diagnosis of fractures of the fifth metacarpal. Emerg Med J 2015; 32: 221-225

[279] Najaf-Zadeh A, Nectoux E, Dubos F et al. Prevalence and clinical significance of occult fractures in children with radiograph-negative acute ankle injury. A meta-analysis. Acta Orthop 2014; 85: 518-524

[280] Szczepaniak J, Ciszkowska-Łysoń B, Śmigielski R et al. Value of ultrasonography in assessment of recent injury of anterior talofibular ligament in children. J Ultrason 2015; 15: 259-266

[281] Tamada I, Mori T, Inoue N et al. An Algorithmic Approach Using Ultrasonography in the Diagnosis of Pediatric Nasal Bone Fracture. J Craniofac Surg 2017; 28: 84-87

[282] Parri N, Crosby B], Mills L et al. Point-of-Care Ultrasound for the Diagnosis of Skull Fractures in Children Younger Than Two Years of Age. J Pediatr 2018; 196: 230-236.e2

[283] Xiong Z, Zeng S, Chen $\mathrm{H}$ et al. Unique finding in congenital muscular torticollis: Clinic screening on the neck of one day old neonate and ultrasonographic imaging from birth through 3 years of follow-up. Medicine 2019; 98: e14794

[284] Gindele A, Schwamborn D, Tsironis F et al. Myositis ossificans traumatica in young children: report of three cases and review of the literature. Pediatr Radiol 2000; 30: 451-459

[285] Abernethy L]. Classification and imaging of vascular malformations in children. Eur Radiol 2003; 13: 2483-2497

[286] Caro-Dominguez P, Navarro OM. Imaging appearances of soft-tissue tumors of the pediatric foot: review of a 15-year experience at a tertiary pediatric hospital. Pediatr Radiol 2017; 47: 1555-1571

[287] Rimondi E, Mavrogenis AF, Errani C et al. Biopsy is not necessary for the diagnosis of soft tissue hemangiomas. Radiol Med 2018; 123: 538-544

[288] Dubois ], Patriquin HB, Garel L et al. Soft-tissue hemangiomas in infants and children: diagnosis using Doppler sonography. Am J Roentgenol 1998; 171: 247-252

[289] Ding AG, Gong X, Li J et al. Role of ultrasound in diagnosis and differential diagnosis of deep infantile hemangioma and venous malformation. J Vasc Surg Venous Lymphat Disord 2019; 7: 715-723

[290] Martin JM, Sanchez S, Gonzalez V et al. Infantile hemangiomas with minimal or arrested growth: A retrospective case series. Pediatr Dermatol 2019; 36: 125-131

[291] Paltiel HJ, Patriquin HB, Keller MS et al. Infantile hepatic hemangioma: Doppler US. Radiology 1992; 182: 735-742

[292] Rodriguez B, Sebaratnam DF, Feito Rodriguez M et al. Cutaneous ultrasound and its utility in Pediatric Dermatology: Part II -Developmental anomalies and vascular lesions. Pediatr Dermatol 2020; 37 : 40-51

[293] Gong X, Ying H, Zhang Z et al. Ultrasonography and magnetic resonance imaging features of kaposiform hemangioendothelioma and tufted angioma. J Dermatol 2019; 46: 835-842
[294] Chang L, Lv D, Jin Y et al. High-frequency color Doppler ultrasound as the first diagnostic and monitoring choice for early superficial highflow vascular malformations. J Med Ultrason 2017; 44: 275-278

[295] Amarneh M, Shaikh R. Clinical and imaging features in fibro-adipose vascular anomaly (FAVA). Pediatr Radiol 2020; 50: 380-387

[296] Meyers AB, Chandra T, Epelman M. Sonographic spinal imaging of normal anatomy, pathology and magnetic growing rods in children. Pediatr Radiol 2017; 47: 1046-1057

[297] Dick EA, de Bruyn R. Ultrasound of the spinal cord in children: its role. Eur Radiol 2003; 13: 552-562

[298] Kang YR, Koo J. Ultrasonography of the pediatric hip and spine. Ultrasonography 2017; 36: 239-251

[299] Karnik AS, Karnik A, Joshi A. Ultrasound Examination of Pediatric Musculoskeletal Diseases and Neonatal Spine. Indian J Pediatr 2016; 83: 565-577

[300] Lam WW, Ai V, Wong V et al. Ultrasound measurement of lumbosacral spine in children. Pediatr Neurol 2004; 30: 115-121

[301] Unsinn KM, Geley T, Freund MC et al. US of the spinal cord in newborns: spectrum of normal findings, variants, congenital anomalies, and acquired diseases. Radiographics 2000; 20: 923-938

[302] Cakmakci E, Cinar HG, Uner C et al. Ultrasonographic clues for diagnosis of spina bifida occulta in children. Quant Imaging Med Surg 2016; 6 : 545-551

[303] Lowe LH, Johanek AJ, Moore CW. Sonography of the neonatal spine: part 2, Spinal disorders. Am J Roentgenol 2007; 188: 739-744

[304] Schenk JP, Herweh C, Gunther P et al. Imaging of congenital anomalies and variations of the caudal spine and back in neonates and small infants. Eur J Radiol 2006; 58: 3-14

[305] Austin MJ, Gerscovich EO, Fogata M et al. Sonographic duplication artifact of the spinal cord in infants and children. J Ultrasound Med 2004; 23: 799-803

[306] Tawfik NA, Ahmed AT, El-Shafei TE et al. Diagnostic value of spinal ultrasound compared to MRI for diagnosis of spinal anomalies in pediatrics. Egypt J Radiol Nucl Med 2020; 51: 18

[307] Oulego-Erroz I, Mora-Matilla M, Alonso-Quintela P et al. Ultrasound evaluation of lumbar spine anatomy in newborn infants: implications for optimal performance of lumbar puncture. J Pediatr 2014; 165: 862 865.e1

[308] Coley BD, Shiels WE $2^{\text {nd }}$, Hogan MJ. Diagnostic and interventional ultrasonography in neonatal and infant lumbar puncture. Pediatr Radiol 2001; 31: 399-402

[309] Muthusami P, Robinson AJ, Shroff MM. Ultrasound guidance for difficult lumbar puncture in children: pearls and pitfalls. Pediatr Radiol 2017; 47: 822-830

[310] Cheung JP, Bow C, Samartzis D et al. Clinical utility of ultrasound to prospectively monitor distraction of magnetically controlled growing rods. Spine J 2016; 16: 204-209

[311] Yoon WW, Chang AC, Tyler P et al. The use of ultrasound in comparison to radiography in magnetically controlled growth rod lengthening measurement: a prospective study. Eur Spine J 2015; 24: 1422-1426

[312] Zheng R, Young M, Hill D et al. Improvement on the accuracy and reliability of ultrasound coronal curvature measurement on adolescent idiopathic scoliosis with the aid of previous radiographs. Spine (Phila Pa 1976) 2016; 41: 404-411

[313] Deeg KH, Lode HM, Gassner I. Spinal sonography in newborns and infants-Part I: method, normal anatomy and indications. Ultraschall in Med 2007; 28: 507-517

[314] Riccabona M. Potenzial role of 3DUS in infants and children. Pediatr Radiol 2011; 41 (Suppl. 1): S228-S237

[315] Riccabona M, Nelson TR, Weitzer C et al. Potenzial of three-dimensional ultrasound in neonatal and paediatric neurosonography. Eur Radiol 2003; 13: 2082-2093 
[316] Vergari C, Dubois G, Vialle R et al. Lumbar annulus fibrosus biomechanical characterization in healthy children by ultrasound shear wave elastography. Eur Radiol 2016; 26: 1213-1217

[317] Shin HJ, Kim MJ, Lee HS et al. Optimal Filum Terminale Thickness Cutoff Value on Sonography for Lipoma Screening in Young Children. J Ultrasound Med 2015; 34: 1943-1949

[318] Albert GW. Spine ultrasounds should not be routinely performed for patients with simple sacral dimples. Acta Paediatr 2016; 105: 890-894

[319] Raza K, Lee CY, Pilling D et al. Ultrasound guidance allows accurate needle placement and aspiration from small joints in patients with early inflammatory arthritis. Rheumatology (Oxford) 2003; 42: 976-979

[320] Patel DN, Nayyar S, Hasan S et al. Comparison of ultrasound-guided vesus blind glenohumeral injections: a cadaveric study. J Shoulder Elbow Surg 2012; 21: 1664-1668

[321] Gilliland CA, Salazar LD, Borchers JR. Ultrasound versus anatomic guidance for intra-articular and periarticular injection: a systematic review. Phys Sports Med 2011; 39: 121-131

[322] Sibbitt WL Jr, Band PA, Kettwich LG et al. A randomized controlled trial evaluating the cost-effectiveness of sonographic guidance for intra-articular injection of the osteoarthritic knee. J Clin Rheumatol 2011; 17: 409-415

[323] Sibbitt WL Jr, Kettwich LG, Band PA et al. Does ultrasound guidance improve the outcomes of arthrocentesis and corticosteroid injection of the knee? Scand J Rheumatol 2012; 41: 66-72

[324] Kim TK, Lee JH, Park KD et al. Ultrasound versus palpation guidance for intraarticular injections in patients with degenerative osteoarthritis of the elbow. J Clin Ultrasound 2013; 41: 479-485

[325] Nam SH, Kim J, Lee JH et al. Palpation versus ultrasound-guided corticosteroid injections and short-term effect in the distal radioulnar joint disorder: a randomized, prospective single-blinded study. Clin Rheumatol 2014; 33: 1807-1814

[326] Soh E, Li W, Ong KO et al. Image guided versus blind corticosteroid injections in adults with shoulder pain: a systematic review. BMC Musculoskelet Disord 2011; 12: 137

[327] Kianmehr N, Hasanzadeh A, Naderi F et al. A randomized blinded comparative study of clinical response to surface anatomy guided injection versus sonography guided injection of hyaluronic acid in patients with primary knee osteoarthritis. Int J Rheum Dis 2018; 21: 134-139

[328] Raeissadat SA, Rayegani SM, Langroudi TF et al. Comparing the accuracy and efficacy of ultrasound-guided versus blind injections of steroid in the glenohumeral joint in patients with shoulder adhesive capsulitis. Clin Rheumatol 2017; 36: 933-940

[329] Hollander JL. Intra-Articular hydrocortisone in the treatment of arthritis. Ann Intern Med 1953; 39: 7 35-746

[330] Canoso J], Naredo E. Aspiration and injection of joints and periaticular tissue intralesional therapy; Rheumatology 5 ed. Mosby Elsevier; 2011. ISBN: 978-0-323-06551-1617-627

[331] Leite VF, Daud Amadera JE, Buehler AM. Viscosupplementation for Hip Osteoarthritis: A Systematic Review and Meta-Analysis of the Efficacy on Pain and Disability, and the Occurrence of Adverse Events. Arch Phys Med Rehabil 2018; 99: 574-583.e1

[332] Trojian TH, Concoff AL, Joy SM et al. AMSSM scientific statement concerning viscosupplementation injections for knee osteoarthritis: importance for individual patient outcomes. Br J Sports Med 2016; 50 : 84-92

[333] Sun Y, Zhang P, Liu S et al. Intra-articular Steroid Injection for Frozen Shoulder: A Systematic Review and Meta-analysis of Randomized Controlled Trials With Trial Sequential Analysis. Am J Sports Med 2017; 45: 2171-2179

[334] Lee LC, Lieu FK, Lee HL et al. Effectiveness of hyaluronic acid administration in treating adhesive capsulitis of the shoulder: a systematic review of randomized controlled trials. Biomed Res Int 2015; 2015: 314120
[335] Bannuru RR, Osani M, Vaysbrot EE et al. Comparative safety profile of hyaluronic acid products for knee osteoarthritis: a systematic review and network meta-analysis. Osteoarthritis Cartilage 2016; 24: 20222041

[336] Gutierrez M, Di Matteo A, Rosemffet M et al. Short-term efficacy to conventional blind injection versus ultrasound-guided injection of local corticosteroids in tenosynovitis in patients with inflammatory chronic arthritis: A randomized comparative study. Joint Bone Spine 2016; 83: 161-166

[337] Ammitzboll-Danielsen M, Ostergaard M, Fana V et al. Intramuscular versus ultrasound-guided intratenosynovial glucocorticoid injection for tenosynovitis in patients with rheumatoid arthritis: a randomised, double-blind, controlled study. Ann Rheum Dis 2017; 76: 666-672

[338] Aslam F, England BR, Cannella A. Ultrasound Doppler and tenosynovial fluid analysis in tenosynovitis. Ann Rheum Dis 2020; 79: 908-913

[339] Srivastava P, Aggarwal A. Ultrasound-guided retro-calcaneal bursa corticosteroid injection for refractory Achilles tendinitis in patients with seronegative spondyloarthropathy: efficacy and follow-up study. Rheumatol Int 2016; 36: 875-880

[340] Burke C], Adler RS. Ultrasound-Guided Percutaneous Tendon Treatments. Am J Roentgenol 2016; 207: 495-506

[341] Morath O, Kubosch EJ, Taeymans ] et al. The effect of sclerotherapy and prolotherapy on chronic painful Achilles tendinopathya systematic review including meta-analysis. Scand J Med Sci Sports 2018; 28: 4-15

[342] Boesen AP, Hansen R, Boesen MI et al. Effect of High-Volume Injection, Platelet-Rich Plasma, and Sham Treatment in Chronic Midportion Achilles Tendinopathy A Randomized Double-Blinded Prospective Study. Am J Sports Med 2017; 45: 2034-2043

[343] Wheeler PC, Mahadevan D, Bhatt R et al. A Comparison of Two Different High-Volume Image-Guided Injection Procedures for Patients With Chronic Noninsertional Achilles Tendinopathy: A Pragmatic Retrospective Cohort Study. J Foot Ankle Surg 2016; 55: 976-979

[344] Krogh TP, Ellingsen T, Christensen R et al. Ultrasound-Guided Injection Therapy of Achilles Tendinopathy With Platelet-Rich Plasma or Saline: A Randomized, Blinded, Placebo-Controlled Trial. Am J Sports Med 2016; 44: 1990-1997

[345] Wang YZ, Han CX, Hao JH et al. Efficacy of platelet-rich plasma injections for treating Achilles tendonitis Systematic review of high-quality randomized controlled trials. Orthopade 2019; 48: 784-791

[346] Zhang Y], Xu SZ, Gu PC et al. Is Platelet-rich Plasma Injection Effective for Chronic Achilles Tendinopathy? A Meta-analysis. Clin Orthop Relat Res 2018; 476: 1633-1641

[347] Montalvan B, Le Goux P, Klouche S et al. Inefficacy of ultrasound-guided local injections of autologous conditioned plasma for recent epicondylitis: results of a double-blind placebo-controlled randomized clinical trial with one-year follow-up. Rheumatology (Oxford) 2016; 55 : 279-285

[348] Chiew SK, Ramasamy TS, Amini F. Effectiveness and relevant factors of platelet-rich plasma treatment in managing plantar fasciitis: A systematic review. J Res Med Sci 2016; 21: 38

[349] Mahindra P, Yamin M, Selhi HS et al. Chronic Plantar Fasciitis: Effect of Platelet-Rich Plasma, Corticosteroid, and Placebo. Orthopedics 2016; 39: E285-E289

[350] Monto RR. Platelet-Rich Plasma Efficacy Versus Corticosteroid Injection Treatment for Chronic Severe Plantar Fasciitis. Foot Ankle Int 2014; 35 : 313-318

[351] Rha DW, Park GY, Kim YK et al. Comparison of the therapeutic effects of ultrasound-guided platelet-rich plasma injection and dry needling in rotator cuff disease: a randomized controlled trial. Clin Rehabil 2013; 27: $113-122$

[352] Dragoo JL, Wasterlain AS, Braun HJ et al. Platelet-Rich Plasma as a Treatment for Patellar Tendinopathy A Double-Blind, Randomized Controlled Trial. Am J Sports Med 2014; 42: 610-618 
[353] Loizides A, Peer S, Plaikner M et al. Ultrasound guided injections of the lumbar spine. Med Ultrason 2011; 13: 54-58

[354] Loizides A, Gruber H, Peer S et al. Ultrasound guided versus CT-controlled pararadicular injections in the lumbar spine: a prospective randomized clinical trial. Am J Neuroradiol 2013; 34: 466-470

[355] Obernauer ], Galiano K, Gruber H et al. Ultrasound-guided versus computed tomography-controlled periradicular injections in the middle and lower cervical spine: a prospective randomized clinical trial. Eur Spine J 2013; 22: 2532-2537

[356] Klauser A, De Zordo T, Feuchtner G et al. Feasibility of ultrasound guided sacroiliac joint injection considering sonoantomic landmarks at two different levels in cadavers and patients. Arthritis Rheum 2008; 59 : 1618-1624

[357] Orr C, Vieira-Sousa E, Boyle DL et al. Synovial tissue research: a state-ofthe-art review. Nat Rev Rheumatol 2017; 13: 463-475

[358] Najm A, Orr C, Heymann MF et al. Success Rate and Utility of Ultrasound-guided Synovial Biopsies in Clinical Practice. J Rheumatol 2016; 43: 2113-2119

[359] Romão VC, Polido-Pereira J, Barros R et al. Efficacy, safety and sample quality of ultrasound-guided synovial needle biopsy in clinical practice and research: a prospective observational study. Arthritis Care Res (Hoboken) 2020; 72: 1497-1505

[360] Humby F, Romão VC, Manzo A et al. A multicenter retrospective analysis evaluating performance of synovial biopsy techniques in Patients With Inflammatory Arthritis: arthroscopic vs. ultrasound guided vs. blind needle biopsy. Arthritis Rheumatol 2018; 70: 702-710

[361] Mankin HJ, Lange TA, Spanier SS. The hazards of biopsy in patients with malignant primary bone and soft-tissue tumors. J Bone Joint Surg Am 1982; 64: 1121-1127

[362] Traina F, Errani C, Toscano A et al. Current concepts in the biopsy of musculoskeletal tumors: AAOS exhibit selection. J Bone Joint Surg Am 2015; 97: e7

[363] Chhabra A, Soldatos T. Soft-tissue lesions: when can we exclude sarcoma? Am J Roentgenol 2012; 199: 1345-1357

[364] Wu JS, Hochman MG. Soft-tissue tumors and tumorlike lesions: a systematic imaging approach. Radiology 2009; 253: 297-316

[365] Kim SY, Chung HW. Small musculoskeletal soft-tissue lesions: USguided core needle biopsy - comparative study of diagnostic yields according to lesion size. Radiology 2016; 278: 156-163

[366] Torriani M, Etchebehere M, Amstalden E. Sonographically guided core needle biopsy of bone and soft tissue tumors. J Ultrasound Med 2002; 21: $275-281$
[367] De Marchi A, Brach Del Prever EM, Linari A et al. Accuracy of core-needle biopsy after contrast-enhanced ultrasound in soft-tissue tumours. Eur Radiol 2010; 20: 2740-2748

[368] Coran A, Di Maggio A, Rastrelli M et al. Core needle biopsy of soft tissue tumors, CEUS vs US guided: a pilot study. J Ultrasound 2015; 18: $335-$ 342

[369] Hoeber I, Spillane AJ, Fisher C et al. Accuracy of biopsy techniques for limb and limb girdle soft tissue tumors. Ann Surg Oncol 2001; 8: 80-87

[370] Yoon MA, Chung HW, Chee CG et al. Risk Factors for Diagnostic Failure of Ultrasound-Guided Core Needle Biopsy of Soft-Tissue Tumors Based on World Health Organization Classification Category and Biologic Potenzial. Am J Roentgenol 2020; 214: 413-421

[371] Yang J, Frassica FJ, Fayad L et al. Analysis of nondiagnostic results after image-guided needle biopsies of musculoskeletal lesions. Clin Orthop Relat Res 2010; 468: 3103-3111

[372] Albrecht E, Mermoud J, Fournier $\mathrm{N}$ et al. A systematic review of ultrasound-guided methods for brachial plexus blockade. Anaesthesia 2016; 71: 213-227

[373] Bendtsen TF, Haskins S, Petersen JAK et al. Do ultrasound-guided regional blocks signify a new paradigm in high-risk patients? Best Pract Res Clin Anaesthesiol 2016; 30: 191-200

[374] Norbury JW, Nazarian LN. Ultrasound-guided treatment of peripheral entrapment mononeuropathies. Muscle Nerve 2019; 60: 222-231

[375] Lewis SR, Price A, Walker KJ et al. Ultrasound guidance for upper and lower limb blocks. Cochrane Database Syst Reviews 2015; 2015: CD006459

[376] Liu SS. Evidence Basis for Ultrasound-Guided Block Characteristics Onset, Quality, and Duration. Reg Anesth Pain Med 2016; 41: 205-220

[377] McCartney C], Lin L, Shastri U. Evidence Basis for the Use of Ultrasound for Upper-Extremity Blocks. Reg Anesth Pain Med 2010; 35: S10-S15

[378] Salinas FV. Evidence Basis for Ultrasound Guidance for Lower-Extremity Peripheral Nerve Block Update 2016. Reg Anesth Pain Med 2016; 41: 261-274

[379] Tran DQ, Boezaart AP, Neal JM. Beyond Ultrasound Guidance for Regional Anesthesiology. Reg Anesth Pain Med 2017; 42: 556-563

[380] Neal JM. Ultrasound-Guided Regional Anesthesia and Patient Safety Update of an Evidence-Based Analysis. Reg Anesth Pain Med 2016; 41: 195-204 